\title{
EVALUATION OF THE EFFECTIVENESS OF DIRECT LIQUID APPLICATION FOR REDUCING CHLORIDE INPUTS TO RYERSON CAMPUS AND URBAN AREAS IN TORONTO
}

By

Kevin Duffin, BSC Dalhousie University, 2017

\begin{abstract}
A MRP
Presented to Ryerson University in partial fulfillment of the Requirements for the degree of Master of Spatial Analysis (MSA) in the Program of Spatial Analysis.
\end{abstract}

Toronto, Ontario, Canada, 2019

(C) Kevin Duffin 


\section{AUTHOR'S DECLARATION}

I hereby declare that I am the sole author of this MRP. This is a true copy of the MRP, including any required final revisions. I authorize Ryerson University to lend this MRP to other institutions or individuals for the purpose of scholarly research. I further authorize Ryerson University to reproduce this MRP by photocopying or by other means, in total or in part, at the request of other institutions or individuals for the purpose of scholarly research. I understand that my MRP may be made electronically available to the public. 


\begin{abstract}
In the winter of $2018 / 19$, Ryerson University began a pilot project which saw the implementation of Direct Liquid Application (DLA) of road salts in select areas within its campus. This study evaluated the reductions in chloride applications that occurred due to the pilot, as well as estimated the chloride reductions that could occur if the project was expanded at Ryerson and if other organizations in Toronto were to adopt DLA. This was done through an analysis of recorded road salt application rates on Ryerson campus. The analysis revealed that the incorporation of DLA into Ryerson's maintenance program reduced chloride inputs to Ryerson Campus. The analysis also illustrated that similar 'savings' could be expected if DLA were expanded to the rest of campus, Green P parking lots, GO train stations, and TTC streetcar waiting areas. Recommendations for future DLA implementation are given.
\end{abstract}




\section{ACKNOWLEDGEMENTS}

We are grateful for the Ryerson Facilities Team, including Dan Batko, Joey De Melo, and Kieran Mccully for their incredible work keeping our campus safe, their contributions to this study and for their willingness to learn and adopt salt saving strategies. We would also like to thank our contacts at the WWF, including Anthony Merante, for helping to fund this project and providing guidance on methodology. Lastly, we are grateful for Ryerson Urban Water for their key role in the implementation of the Ryerson Road Salt Reduction Pilot Project.

I would also like to thank Dr. Claire Oswald for her guidance throughout this project. 


\section{TABLE OF CONTENTS}

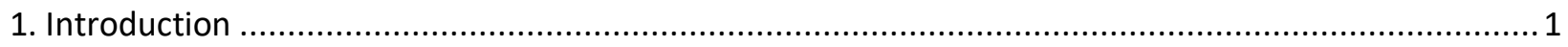

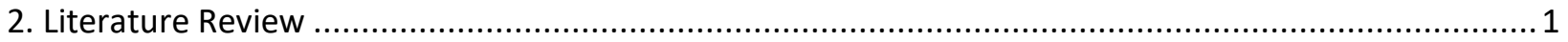

2.1 Utility of Road Salts and De-icing Chemical for Winter Maintenance ........................................ 1

2.2 Environmental Impacts of Chloride-Based Road Salts ......................................................... 2

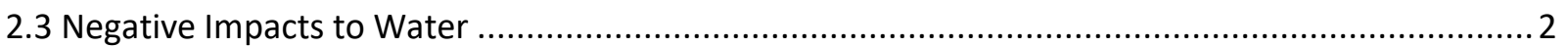

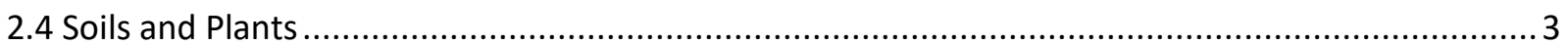

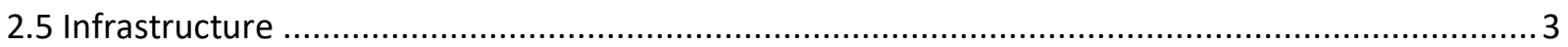

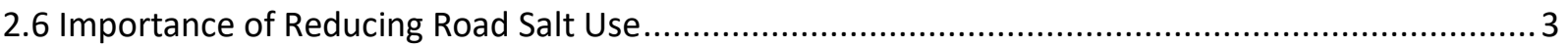

2.7 Anti Icing and Direct Liquid Application .................................................................................. 4

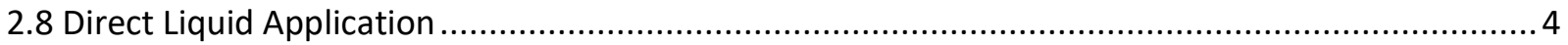

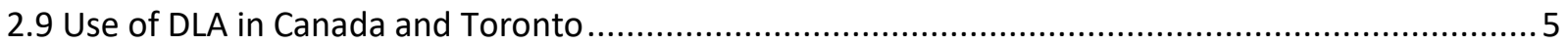

3. Ryerson Road Salt Reduction Project and Research Questions ................................................... 5

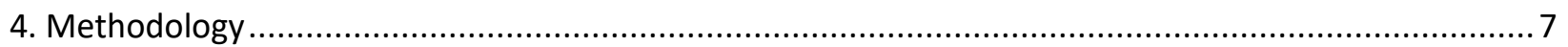

4.1 Pilot Salt Reduction Zones and Application of Brine ................................................................. 7

4.2 Statistical Comparison of Chloride Application Rates............................................................ 8

4.3 Estimation of Chloride Reduction during Recorded Salting Events ............................................. 9

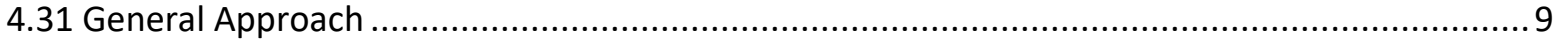

4.32 Weather specific replacement mass the calculation ....................................................... 11

4.4 Scaling Chloride Reductions to Whole 2018/19 Salting Season at Ryerson ................................ 12

4.5 Estimation of Reduction in Chloride Inputs and Material Cost if DLA Use was Expanded to Ryerson, Metrolinx Go Stations, King Streetcar Stops and Green P Parking Lots within the City of Toronto ...... 16

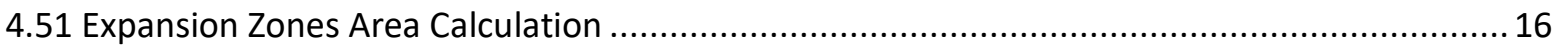

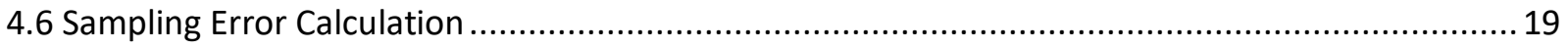

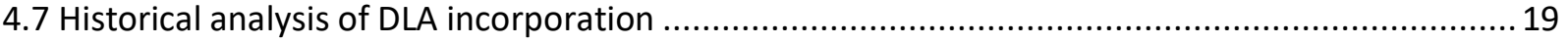

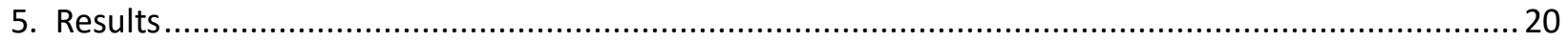

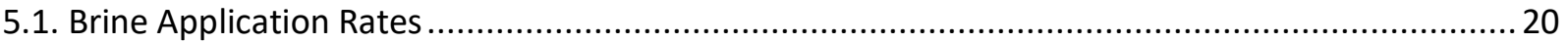

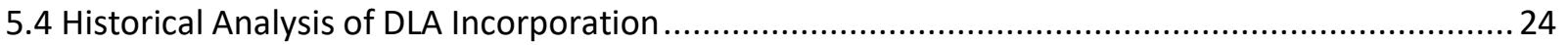

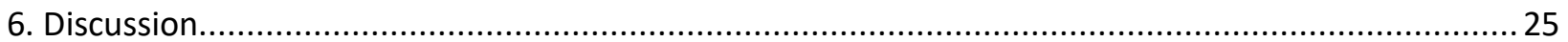

6.1 Effectiveness of DLA at Reducing Chloride Inputs to the Environment from Ryerson University ... 25

6.2 Cost Savings Associated with the Use of DLA on Ryerson University Campus.............................. 25

6.3 Chloride Diversion and Cost Savings Associated with Case Studies ........................................... 26 


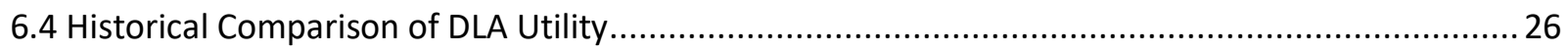

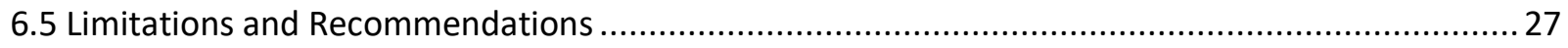

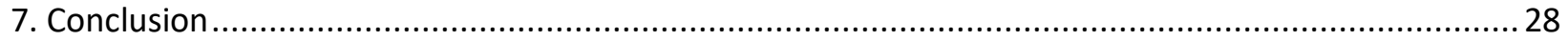

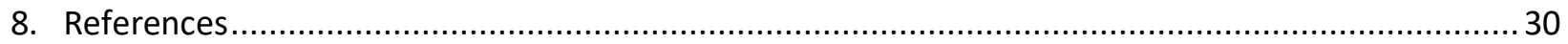




\section{LIST OF TABLES}

Table 1. Brine and rock salt application event dates, event characteristics and mean $\mathrm{Cl}^{-}$application rate

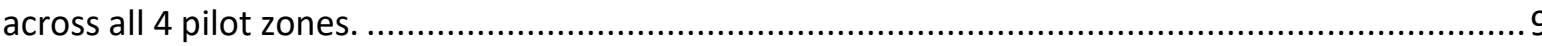

Table 2. Amalgamated weather classification system and number of events observed during the 2018/19 pilot study.

Table 3. Mean $\mathrm{Cl}^{-}$application rate of brine and rock salt application events grouped by weather categories. 20

Table 4. Summary Statistics of Historic Climate Data Analysis Error! Bookmark not defined. 


\section{LIST OF FIGURES}

Figure 1. Figure 1. Ryerson Road Salt Reduction Pilot Zones and location of Ryerson University in

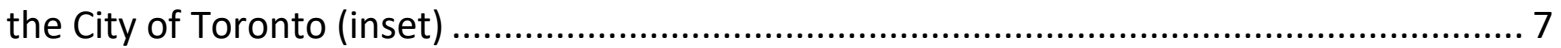

Figure 2. Workflow for the estimation of $\mathrm{Cl}^{-}$savings over observed salting events. ................. 12

Figure 3. Workflow for the $\mathrm{Cl}^{-}$savings estimation for entire 2018/19 winter season................ 15

Figure 4. Impermeable Surfaces under the jurisdiction of Ryerson's Facilities Maintenance Team.

Figure 5. Mimico Station (Top Left), Scarborough Station (Top Right), Guildwood Station (Bottom Left), and the locations of all Lakeshore East and West Metrolinx Go Stations

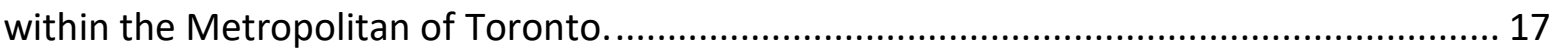

Figure 6. Example of King Street Bus/Streetcar Transit Stop (Urban Toronto, 2017)................ 17

Figure 7. Green P parking lots within the Metropolitan of Toronto ........................................ 18

Figure 8. Interzonal Variation in Brine (left) and Rock Salt (right) $\mathrm{Cl}^{-}$application rates.............. 21

Figure 9. Estimated Weather Specific and Non- Weather Specific $\mathrm{Cl}^{-}$reductions that occurred

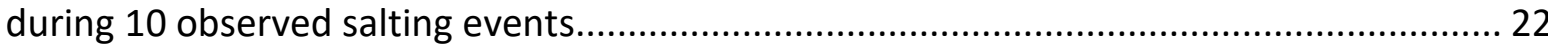

Figure 10. Weather and Non- Weather Specific $\mathrm{Cl}$ - reduction estimations for DLA use at Ryerson Pilot Zones throughout 2018/19 winter season............................................................ 22

Figure 11. Estimated Weather Specific and Non- Weather Specific $\mathrm{Cl}^{-}$reductions for Ryerson Campus, Green P Parking Lots, Metrolinx Go Stations, and TTC King Street Transit Stops.. 23 Figure 12. Increase in proportion of total salting events requiring brine between 1938 and 2018 


\section{Introduction}

Chloride based road salts used for ice and snow control are an integral aspect of winter safety maintenance practices (City of Toronto, 2016). However due to the adverse impacts of chloride pollution, primarily to aquatic ecosystems (Beggel \& Geist, 2015; CEQG, 2011; Corsi, Graczyk, Geis, Booth, \& Richards, 2010; Fay \& Shi, 2012; Hintz \& Relyea, 2017; Sanzo \& Hecnar, 2006), many organizations and municipalities are attempting to reduce their road salt use by adopting more efficient salt application techniques (Transportation Association of Canada, 2013). Direct Liquid Application (DLA), which involves the application of liquid salt brine to target surfaces, is one such technique (Crewe \& Gowda, 2018; Fonnesbech, 2007; S. M. K. Hossain, 2014). Although many municipalities have adopted DLA for select roadway salting practices (Transportation Association of Canada, 2013), DLA is not widely used by organizations for common non- roadway salting. Ryerson's Road Salt Reduction Pilot project, which has seen the implementation of DLA on Ryerson's Campus, was designed to illustrate that the implementation of DLA for non- roadway surface salting is a cost-effective approach to reduce the chloride requirements associated with winter maintenance practices. This Major Research Project presents the results of the 2018/19 Ryerson Road Salt Reduction Pilot Project and uses the associated data to explore the benefits of expanding the use of DLA to other organizations in the City of Toronto.

\section{Literature Review}

\subsection{Utility of Road Salts and De-icing Chemical for Winter Maintenance}

In northern regions, winter roadway conditions pose serious threats to pedestrian and driver safety. In Canada, $12 \%$ of all traffic related fatalities and injuries are associated with these adverse conditions (Kelsall \& Redelmeier, 2016). To increase winter transportation safety, winter maintenance managers rely heavily upon chemicals to remove snow and ice from roads and walkways. These chemicals typically lower the freezing point of water, melting snow and ice in below zero conditions. Many chemicals are used for this purpose, however due to its effectiveness, low price and abundance, the majority of organisations, institutions and governments use Sodium Chloride ( $\mathrm{NaCl}$ (Baltrènas \& Kazlauskienè, 2009; Kelly et al., 2010; Laffray et al., 2018). Approximately 4.9 billion tonnes of $\mathrm{NaCl}$ are used on Canadian roads each year (Environment Canada, 2001), and the City of Toronto alone applied 812,534 tonnes of road salt to its sidewalks and roadways between 2010 and 2016 (City of Toronto, 2016; Environment Canada, 2001). 


\subsection{Environmental Impacts of Chloride-Based Road Salts}

Despite their utility for snow and ice control, chloride-based road salts have serious negative environmental impacts. In 1999, a Canadian federal environmental assessment found $\mathrm{NaCl}$ based road salts to be toxic as defined by Section 64 of CEPA 1999 due to the tangible threat of serious or irreversible environmental damage as a result of $\mathrm{NaCl}$ road salt use (Environment Canada, 2001). However, the Ministers' Expert Advisory Panel was forced to consider the safety benefits of road salts, as any substance control measures developed through federal toxic substance assessments must not compromise human safety. Due to the utility of road salts in winter maintenance, it was determined $\mathrm{NaCl}$ would not be regulated by law (Environment Canada, 2001).

\subsection{Negative Impacts to Water}

In water, $\mathrm{NaCl}$ readily dissociates into $\mathrm{Na}^{+}$and $\mathrm{Cl}^{-}$(Kotalik, Clements, \& Cadmus, 2017). The $\mathrm{Cl}^{-}$ion is not absorbed, metabolized or broken down by any natural process and therefore the dispersion of the $\mathrm{Cl}^{-}$ will be identical to the water which carries it (Siegel, 2007). The majority of $\mathrm{Cl}^{-}$particles will travel quickly over impermeable surfaces and through storm sewers into regional lakes, rivers and streams (Meriano, Eyles, \& Howard, 2009; Ramakrishna \& Viraraghavan, 2005). Melt events following winter storms often results in stream $\mathrm{Cl}^{-}$concentrations spikes over $640 \mathrm{mg} / \mathrm{L}$ (Perera, Gharabaghi, \& Noehammer, 2009), which create conditions that are acutely toxic to fish, macroinvertebrates, insects, amphibians and aquatic plant species (Beggel \& Geist, 2015; CEQG, 2011; Corsi et al., 2010; Fay \& Shi, 2012; Hintz \& Relyea, 2017; Sanzo \& Hecnar, 2006). Where dissolved road salt interacts with permeable surfaces, such as ditches and lawns, chloride can percolate through the soil and into the groundwater table. Slow flowing subsurface pathways gradually transport this $\mathrm{Cl}^{-}$into surface waters, resulting in the consistent input of $\mathrm{Cl}^{-}$into surface waters well into the spring and summer seasons. This process often elevates surface water $\mathrm{Cl}^{-}$content above long term (chronic) protection guidelines $\left(120 \mathrm{mgCl}^{-} / \mathrm{L}\right.$ ) which can impact the survival, growth and reproduction of aquatic organisms during the spring and summer growing season (CEQG, 2011; Oswald, Giberson, Nicholls, Wellen, \& Oni, 2019; Wallace \& Biastoch, 2016). Upon dissolution, the transport of the $\mathrm{Na}^{+}$ion is reduced due to cation exchange reactions occurring in the soils near the application location. However, after several years of $\mathrm{NaCl}$ application, the soil's $\mathrm{Na}^{+}$ exchange capacity can become exhausted (Labadia \& Buttle, 1996) and the $\mathrm{Na}^{+}$will then proceed to infiltrate into groundwater. This can compromise aquifer-based drinking water sources as increased $\mathrm{Na}+$ consumption elevates the risk of hypertension (Daley, Potter, \& Mcdowell, 2009; Robinson, Hasenmueller, \& Chambers, 2017). The contamination of groundwater due to $\mathrm{NaCl}$ has been well documented in Toronto (Howard \& Maier, 2007; Labadia \& Buttle, 1996; Pilon \& Howard, 1987) as 
several aquifers near the cities urban centers have been found to possess elevated $\mathrm{Na}^{+}$and $\mathrm{Cl}^{-}$contents. The continued use of road salts throughout the future expansion of Toronto is also expected to jeopardize aquifers currently used for drinking water (Howard \& Maier, 2007).

\subsection{Soils and Plants}

Soils exposed to $\mathrm{NaCl}$ can experience altered acidity, displacement of nutrient cations, reductions in soil permeability, and increases in the mobilization of heavy metals (Cunningham, Snyder, Yonkin, Ross, \& Elsen, 2008; Fay \& Shi, 2012; Laffray et al., 2018; Ramakrishna \& Viraraghavan, 2005). These processes often cause urban soils to become toxic due to their high exposure to chloride-based road salts (Cunningham et al., 2008). $\mathrm{NaCl}$ exposure also significantly affects plant health. Depending on the plant species, vegetation exposed to $\mathrm{NaCl}$ can experience a reduction in biomass, injury, disease and death. A study in Toronto found that high exposure to $\mathrm{NaCl}$ road salt was associated with roadside tree mortality and declining tree foliage patterns (Ordóñez-Barona, Sabetski, Millward, \& Steenberg, 2018).

\subsection{Infrastructure}

Sodium chloride is a very corrosive chemical and causes extensive damage to urban infrastructure. $\mathrm{NaCl}$ exposure can critically weaken the concrete and embedded rebar components of reinforced concrete structures. This process is considered the most damaging mechanism to urban bridges and buildings worldwide (Hájková, Šmilauer, Jendele, \& Červenka, 2018; Stewart \& Vu, 2000). Sodium chloride has also been shown to corrode metal vehicle components (Li et al., 2013). It is estimated that the cost of corrosion damage and protection practices for the highway and automobile industry in the United States costs between 16-19 billion dollars per year (Kelly et al., 2010).

\subsection{Importance of Reducing Road Salt Use}

The negative environmental impacts of $\mathrm{NaCl}$ have led to the development of a variety of alternative deicing and anti-icing chemicals, including potassium formate ( $\mathrm{KCHOO}$ ), beet-sugar and salt brine de-icers (Fu, Omer, \& Jiang, 2012; Rasa, Peltovuori, \& Hartikainen, 2006). Although many of these chemicals have shown to be effective snow and ice control substances, the majority have their own set of associated negative environmental impacts and are often more costly to produce (Kelly et al., 2010). As a result, it is likely that sodium chloride will continue to be widely used due to its low cost, performance and the nature of existing infrastructure (Baltrènas \& Kazlauskienè, 2009).

However, many organizations have begun prioritizing the reduction of road salt use through the incorporation of novel techniques and industry-defined best practices. In Canada, the Canadian Code of Practice for the Environmental Management of Road Salts outlines several of these best practices 
(Environment and Climate Change Canada, 2016), such as the use of electronic salt spreaders, the prewetting of roads salts prior to application, and the use of road weather information systems (Environment Canada, 2012)The implementation of these strategies has been successful in reducing the amount of road salt needed to ensure safe winter conditions in several municipalities (Transportation Association of Canada, 2013). For example, in the Toronto area, the mean normalized road salt application rate decreased by $26 \%$ in the period after the code of conduct best practices were implemented (Kilgour, Gharabaghi, \& Perera, 2013). These reductions in $\mathrm{Cl}^{-}$use have reduced the environmental harm caused by winter road maintenance in Toronto. It is estimated that the $26 \%$ reduction in road salt application rates has benefitted up to $14 \%$ of freshwater taxa due to the associated reductions in acute and chronic chloride levels (Kilgour et al., 2013). Despite these successes, road salt pollution remains a massive environmental issue in the City of Toronto, with many local waterways experiencing $\mathrm{Cl}^{-}$levels between 125 - $775 \mathrm{mg} \mathrm{Cl} / \mathrm{L}$ (WWF, 2019).

\subsection{Anti Icing and Direct Liquid Application}

A technique that is often included in industry best practices is the use of Direct Liquid Application (DLA) of road salts during the anti-icing of roads and walkways. Anti-icing refers to the pre-treatment of target surfaces with road salt prior to winter precipitation events. The interaction between the road salt and the precipitation creates a liquid layer of brine in-between the pavement and the accumulating snow or ice. This prevents the ice from bonding to the pavement, increasing the ease of ice and snow removal and reducing the need of additional salts applications to remove bonded ice (Perera et al., 2009).

\subsection{Direct Liquid Application}

DLA involves the use of a liquid chloride-based brine for anti-icing. Various chemical concentrations are utilized, however the most common is a $23.3 \% \mathrm{NaCl}$ brine solution. This method has been shown to reduce the quantity of chloride needed during anti-icing (Crewe \& Gowda, 2018; Fonnesbech, 2007; S. M. K. Hossain, 2014) in part due to the increased retention of the chemicals on the target surface (Fonnesbech, 2007).

Following brine application, the water in the solution evaporates leaving behind a layer of sodium chloride particles on the target surface. This method more evenly distributes the $\mathrm{NaCl}$ over the target surface, offering better ice and snow protection than conventional road salts (Alger, Adam, \& Beckwith, 1994). Additionally, the particles left behind by the brine are less likely to be thrown off the target surface during application and due to vehicle and pedestrian traffic. A study by Fonnesbach (2007) found that after 2 hours of low vehicle traffic, surfaces applied with brine retained $21 \%$ more $\mathrm{NaCl}$ than 
those applied with conventional rock salt. The study also found that following 2 hours of heavy vehicle traffic, brined surfaces retained $30 \%$ more $\mathrm{NaCl}$.

However, it is agreed upon that brine is not effective during winter storm events with high accumulation values or liquid precipitation (Schlup, 1993). These types of winter storms can cause dilution of the $\mathrm{NaCl}$, causing the $\mathrm{Cl}^{-}$to be removed from the target surface (Cuelho, Harwood, Akin, \& Adams, 2010; S. M. K. Hossain, 2014).

\subsection{Use of DLA in Canada and Toronto}

In 2009, 35\% of municipal road organizations had incorporated the use of DLA into their winter ice and snow control strategies (Environment Canada, 2012). The City of Toronto began utilizing salt brine and DLA in the winter of 2003-04 (City of Toronto, 2016). Currently, the City of Toronto utilizes approximately 2,000,000 liters of salt brine per year and estimates that salt trucks outfitted with the capacity for DLA experience a 10\% reduction in salt use (Transportation Association of Canada, 2013). However, the City of Toronto currently does not have the capacity to utilize DLA on the entirety of Toronto's road networks, only utilizing this technique for salt applications to priority areas such as steep hills and bridges (City of Toronto, 2016).

\section{Ryerson Road Salt Reduction Project and Research Questions}

In an effort to reduce its annual chloride use, over the winter of 2018/19 Ryerson University experimented with the DLA of a $23.3 \% \mathrm{NaCl}$ brine for anti-icing within its downtown campus (Figure 1). Throughout the winter season, in response to select forecasted precipitation events, brine was applied to four pilot areas in the place of conventional rock salt. Additionally, the total amounts of brine and rock salt applied within the test areas were recorded, along with the air and surface temperatures, and expected precipitation event characteristics for 10 winter precipitation events.

The facilities maintenance team has stated that salt use was dramatically reduced due to the use of brine, possibly by as much as $4000 \mathrm{~kg}$ (D. Batko, pers. comm.). However, it is important to empirically quantify these values so that the groups involved in the planning of this project, such as the Ryerson Sustainability Office and Ryerson Urban Water, can accurately disseminate the results and justify the continuation of the project at Ryerson. Therefore, the primary goal of this research is to provide Ryerson facilities, the Ryerson Sustainability office, Ryerson Urban Water, and other interested external 
organizations, with an understanding of the impacts of the incorporation of DLA during the winter of 2018/19 in terms of $\mathrm{NaCl}, \mathrm{Cl}^{-}$and financial savings.

The expansion of DLA at Ryerson is also of interest to Ryerson facilities, the Ryerson Sustainability office, and Ryerson Urban Water as these groups are interested in furthering the sustainability of Ryerson Campus. With the aim of providing justification for this expansion, this study will also estimate the material and financial savings that would occur if DLA was used on all areas of Ryerson Campus.

Additionally, alternatives to road salt and road salt reduction strategies have become a common topic of discussion in Toronto and Canada over the past several years. Many organizations are investigating strategies to reduce their $\mathrm{NaCl}$ use due to the large environmental impact of these chemicals. Advocacy groups, particularly the World Wildlife Fund, are actively seeking examples and or case studies of brine pilot projects to promote the adoption of DLA to external organizations. Therefore, an additional goal of this project is to illustrate the utility of DLA to reduce $\mathrm{NaCl}$ use. Not only will the savings experienced by Ryerson act as an example of the utility of DLA, but the data collected from the Ryerson Road Salt Reduction project will be used with GIS data and data analysis techniques to estimate the material and financial savings that could occur from the adoption of DLA by specific organizations within the City of Toronto. These are referred to as the DLA expansion case study scenarios.

Lastly, a series of recommendations will be developed regarding the use of brine, and the development and improvement of non- roadway DLA pilot projects such as the Ryerson Road Salt Reduction Project.

This study will therefore address the following research questions:

1. Was the use of the DLA an effective approach for reducing chloride inputs to the Ryerson University campus over the 2018/19 winter season?

2. What is the estimated reduction in (i) chloride inputs and (ii) material cost if DLA use was expanded to all areas on Ryerson University campus, select Go Stations, TTC streetcar stops, and Green P parking lots in the City of Toronto?

3. What is the estimated reduction in $\mathrm{Cl}^{-}$and material cost from the use of DLA in a variety of winter scenarios? 


\section{Methodology}

\subsection{Pilot Salt Reduction Zones and Application of Brine}

Ryerson University is a mid-sized urban university within the dense area of downtown Toronto, Canada

(Figure 1). The Ryerson campus is quite compact, contained within two square city blocks (Gerrard St east to Dundas St east between Yonge and Jarvis St). The Ryerson maintenance team is responsible for maintaining safe winter conditions on all walkways, sidewalks, and stairs on Ryerson property, as well as the public sidewalks adjacent to Ryerson campus buildings. This includes snow removal and regular surface salting during the winter season. The maintenance team is not responsible for the maintenance of the public roads within the campus area, however they are responsible for the two private walking streets on campus.

The four brine pilot zones utilized in this study were located on the western area of campus, between Yonge and Church and Gerrard St. and Dundas St.

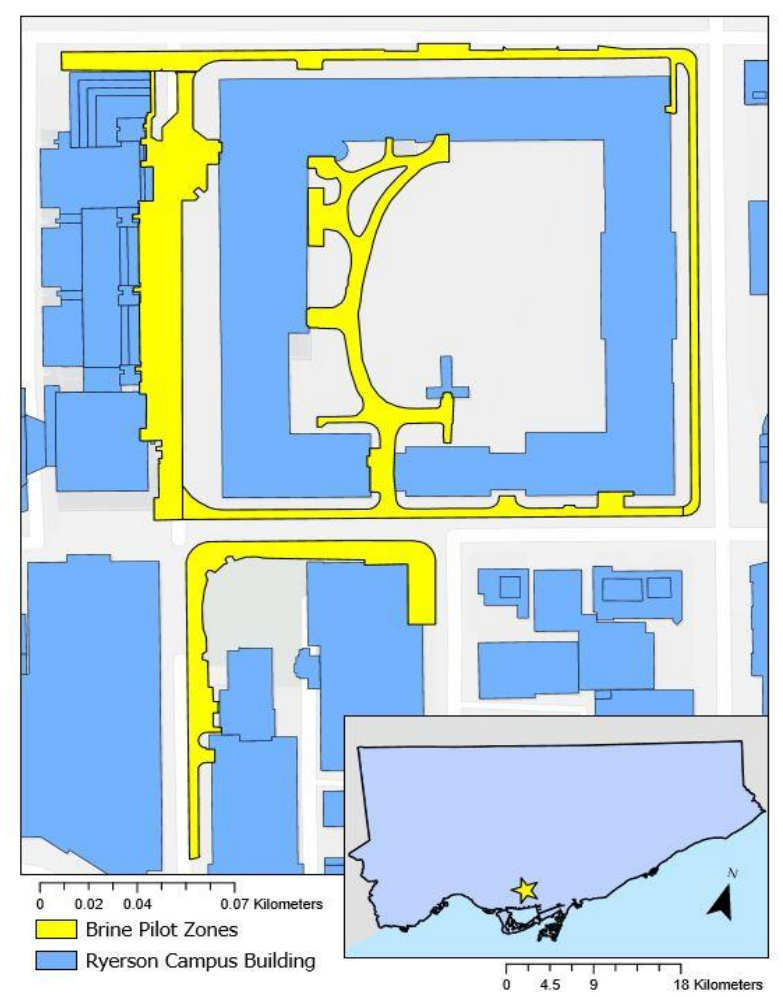

Figure 1. Figure 1. Ryerson Road Salt Reduction Pilot Zones and location of Ryerson University in the City of Toronto (inset)

(Figure 1). These zones were selected by the maintenance staff based on their knowledge of campus salting and foot traffic requirements, and due to their proximity to the Ryerson maintenance garage where the brine equipment is stored.

Over the 2018/19 winter season, the Ryerson maintenance staff utilized a $23.3 \% \mathrm{NaCl}$ brine solution for anti-icing during select winter storm events. In accordance to standard best practices and academic research (City of Toronto, 2016; Environment and Climate Change Canada, 2016; Environment Canada, 2012), brine was primarily utilized for anti-icing during winter storms characterized by low to moderate levels of snow fall without the presence of liquid precipitation. Specifically, maintenance staff aimed to utilize brine for any winter precipitation events in which forecasts predicted up to $3 \mathrm{~cm}$ of snow accumulation and less than $1 \mathrm{~mm}$ of rainfall. Conventional rock salt was used for anti-icing for any winter precipitation event with greater than $3 \mathrm{~cm}$ of forecasted accumulation and greater than $1 \mathrm{~mm}$ of freezing rain. Additionally, anti-icing with brine or rock salt was only performed by Ryerson staff when 
temperatures were forecasted between 0 and -12 degrees Celsius. This is in response to the decreased effectiveness of $\mathrm{NaCl}$ at low temperatures (Crewe \& Gowda, 2018; Cuelho et al., 2010; Fay \& Shi, 2012; S. M. K. Hossain, 2014).

The applications of the $\mathrm{NaCl}$ brine were carried out using an automated liquid sprayer mounted on a campus sidewalk plow. Manual hose sprayers were also used to apply brine to areas inaccessible to the campus vehicle. Conventional rock salt applications were done using a standard salt spreader mounted on a similar vehicle and done manually by hand. Of the 10 recorded salting events, only brine was utilized for 5 , and only rock salt was used for the remainder. Each precipitation event had at least one application of either salt or brine in each test zone, and several have two documented applications. Two applications occurred during relatively long duration storm events. The amount of snow accumulation and the presence of freezing rain was also recorded; however, the amount or intensity of rain was not recorded. To provide an estimate of the amount of rain during salting events, daily total rainfall data was acquired from the Canadian Historic Climate Database Pearson International Airport Weather station (Government of Canada, 2019). This is the most proximate weather station to Ryerson that reports rain accumulation daily. The utilization of the historic weather data introduced a small degree of error into all sections of this analysis that utilized this data. This is due to the minor variations in weather patterns observed between the Pearson International airport and Ryerson's campus.

On dates which had two salting events, and freezing rain was indicated for both salting events, the daily total rainfall was split evenly between the two salting events. The salting events, the event type and their associated mean $\mathrm{Cl}^{-}$application rates can be seen in Table 1.

\subsection{Statistical Comparison of Chloride Application Rates}

Prior to the estimation of material and financial savings, it was necessary to confirm that DLA required less $\mathrm{Cl}^{-}$than conventional rock salt. Various other road salt related studies that have utilized statistical ttesting to confirm an observed difference between two salt application methods. For example, t-testing has been used to compare the performance of liquid de-icing agents, and to compare the melting speed of $\mathrm{NaCl}$ road salts on various surface types (Fu et al., 2012; S. M. K. Hossain, 2014).

Rather than utilizing t-testing to evaluate the performance of the chemicals themselves, $t$-testing was used to assess the performance of the application method in terms of the amount of $\mathrm{Cl}^{-}$applied to surfaces. Specifically, independent sample t testing was used to assess whether the difference in mean brine event and rock salt event $\mathrm{Cl}^{-}$application rates were statistically significant. Independent sample t- 
testing is used to assess the difference between observed values with different grouping variable. In this case, the grouping variable used was the method of $\mathrm{NaCl}$ application. The mean $\mathrm{Cl}^{-}$application rate per event was computed for every salt application event via excel. SPSS statistical software was then used to assess the distribution of the data and run the independent sample $t$ test.

Table 1. Brine and rock salt application event dates, event characteristics and mean $\mathrm{Cl}^{-}$application rate across all 4 pilot zones.

\begin{tabular}{|c|c|c|c|}
\hline Brine Event Date & Event Characteristics & Application Method & Mean $\mathrm{Cl}^{-} \mathrm{Kg} / \mathrm{m}^{2}$ \\
\hline 2019-01-20 & Snowfall $(3 \mathrm{~cm})$ & Brine & 0.0077 \\
\hline 2019-02-05 & Freezing Rain ( $<1 \mathrm{~mm}$ daily total) & Brine & 0.0175 \\
\hline 2019-02-06 & Snowfall $(2 \mathrm{~cm})+$ Freezing Rain $(7.4 \mathrm{~mm})$ & Brine & 0.0196 \\
\hline 2019-02-11 & Snowfall $(3 \mathrm{~cm})$ & Brine & 0.0105 \\
\hline 2019-03-02 & Snowfall $(3 \mathrm{~cm})$ & Brine & 0.0154 \\
\hline 2019-01-23 & Snowfall $(2 \mathrm{~cm})+$ Freezing Rain $(3.6 \mathrm{~mm})$ & Rock Salt & 0.0361 \\
\hline 2019-01-23 & Snowfall $(<1 \mathrm{~cm})+$ Freezing Rain $(3.6 \mathrm{~mm})$ & Rock Salt & 0.0328 \\
\hline 2019-02-06 & Freezing Rain (7.4 mm) & Rock Salt & 0.0320 \\
\hline 2019-02-07 & Freezing Rain (0.6 mm) & Rock Salt & 0.0189 \\
\hline 2019-03-02 & Snowfall $(2 \mathrm{~cm})$ & Rock Salt & 0.0268 \\
\hline
\end{tabular}

Additionally, the variability of $\mathrm{Cl}^{-}$application rates observed between zones was assessed by creating a series of box plots and visually assessing the distribution of the $\mathrm{Cl}^{-}$ application rates observed in each zone. If significant variability were to be found between zones it would not be reasonable to utilize the mean $\mathrm{Cl}^{-}$applications rate from all pilot zones in the estimation of $\mathrm{Cl}^{-}$savings. 4.3 Estimation of Chloride Reduction during Recorded Salting Events

\subsection{General Approach}

Studies assessing the performance of salt application techniques often utilize and record each type of salt application technique side by side, within the same general environment and weather conditions (Fu et al., 2012; S. M. K. Hossain, 2014; S. M. K. Hossain et al., 2016). This allows for the comparison of performance in a way that controls for the effect of weather conditions. As these side by side comparison were not performed in the Ryerson Road Salt Reduction Pilot, a different method will be 
employed to estimate $\mathrm{Cl}^{-}$reductions. The hypothetical amount of $\mathrm{Cl}^{-}$that would have been applied to the test zones if only rock salt had been used over the 10 recorded events will be estimated. This hypothetical value will be referred to as the "business as usual" 2018/19 $\mathrm{Cl}^{-}$mass (BAU). The BAU will then be compared to the actual amount of $\mathrm{Cl}^{-}$applied during those events, referred to as the "actual" 2018/19 $\mathrm{Cl}^{-}$mass (ACT). Computing the difference between the BAU and the ACT mass values will produce an estimation of $\mathrm{Cl}^{-}$reductions experienced in 2018/19. Although this method is less ideal, this is the most feasible method of $\mathrm{Cl}^{-}$reduction estimations available given the nature of the data.

Additionally, the estimations are based on observed salt application events, which increase the validity of the estimates.

To calculate the BAU mass value, the 5 recorded $\mathrm{Cl}^{-}$masses applied via brine were replaced with masses of $\mathrm{Cl}^{-}$derived from observed 2018/19 rock salt application rates and the areas of the brine pilot zones. These values are referred to as the "replacement" $\mathrm{Cl}^{-}$mass values.

A possible method of replacement mass estimation that was investigated was the use of a regression analysis. Multiple regression could have been used to relate environmental characteristics, such as accumulation of snow and rain, and temperature to rock salt application rates observed during rock salt application events. If successful, this relationship could have been used in conjunction with the observed weather characteristic of the brine application events to statistically predict each replacement mass. However, the pilot project dataset contained too few data points to perform a valid multiple regression as only 20 data points were present in the dataset (Bonett \& Wright, 2011).

Instead, a BAU scenario was developed using the total average rock salt $\mathrm{Cl}^{-}$application rate across all recorded rock salt application events. The masses of $\mathrm{Cl}^{-}$applied during the 5 brine application events were replaced by replacement masses derived from this total average $\mathrm{Cl}^{-}$application rate and the total area of the pilot zones. These replacement values are referred to as the "non-weather specific" replacement values and $\mathrm{Cl}^{-}$estimations.

However, as several of the observed rock salt application events took place during conditions which required a larger amount of maintenance (i.e., heavy snow and rain), this estimation may overestimate the replacement masses and therefore the savings experienced in $2018 / 19$. To account for this issue, "weather specific" replacement masses and $\mathrm{Cl}^{-}$estimations were also generated. In these estimation, each brine event $\mathrm{Cl}^{-}$mass was replaced using a rock salt $\mathrm{Cl}^{-}$application rate derived from rock salt application events observed in similar environmental conditions as the brine event being replaced. This 
was expected to increase the accuracy of the replacement mass estimation by accounting for environmental conditions. However, this may have reduced the robustness of the estimate as fewer data points were utilized to generate each replacement $\mathrm{Cl}^{-}$mass.

\subsection{Weather specific replacement mass the calculation}

To generate the weather specific BAU estimation, a weather event classification system was developed

to classify the environmental conditions observed during each brine and rock salt application event. This was done using existing weather classification systems developed for public policy and academic research (Matthews \& Andrey, 2017; Zhou, Mcmahon, Walton, \& Lewis, 2000). Snow accumulation was classified into three groups, Light Snow (0.2 - $1.9 \mathrm{~cm}$ accumulation), Moderate Snow (1.91 - $4.9 \mathrm{~cm}$ accumulation), and Heavy Snow $(>4.9 \mathrm{~cm})$. These classifications were based on the weather classification system used in the Ontario Ministry of Transportation's Weather Severity Index (Matthews \& Andrey, 2017). This classification system was developed using an optimization algorithm which directly related daily weather conditions with associated maintenance demand. For example, the algorithm determined that snow accumulation above $1.9 \mathrm{~cm}$ requires medium maintenance, while accumulation under that threshold typically require low maintenance activities. This is an optimal weather classification system for use in this analysis as separating the application rates based on maintenance requirements is the primary concern.

Liquid precipitation values were classified into six categories, No rain $(0 \mathrm{~mm})$, Light rain $(0.1-0.9 \mathrm{~mm})$, Showers (1 - $2.9 \mathrm{~mm})$, Rain (3.0 -9.9 mm), Heavy Rain (10.0 - $24.9 \mathrm{~cm})$ and Very Heavy Rain (>24.9 cm). This classification system was adopted from a study by Zhou et al, 2000 who developed a classification system to assess daily rainfall values in Australia (Zhou et al., 2000). This classification system generally agrees with many daily total rainfall classification systems used in Canada (Zhang, Hogg, \& Mekis, 2001; Prairie Climate Center, 2019), however it has a larger number of criteria and therefore will increase the accuracy of the weather classifications used in this analysis. Mixed snow and rain precipitation events were classified using a combination of the two previous systems. For example, "Light snow, Light rain".

Each salt application event was classified into the above categories. Due to the limited number of recorded salting events, not all the categories were filled. However, each brine event did have a corresponding rock application event classified into the same category, allowing for the estimation of the $\mathrm{BAU} \mathrm{Cl}^{-}$mass value. 
The weather specific replacement masses were then calculated using the average $\mathrm{Cl}^{-}$application rate of all rock salt application events grouped into the same weather category as the brine event being replaced, and the total area of the pilot zones. The weather specific BAU masses were then computed, and the difference between these BAU and $\mathrm{ACT} \mathrm{Cl}^{-}$masses were calculated (Figure 2).

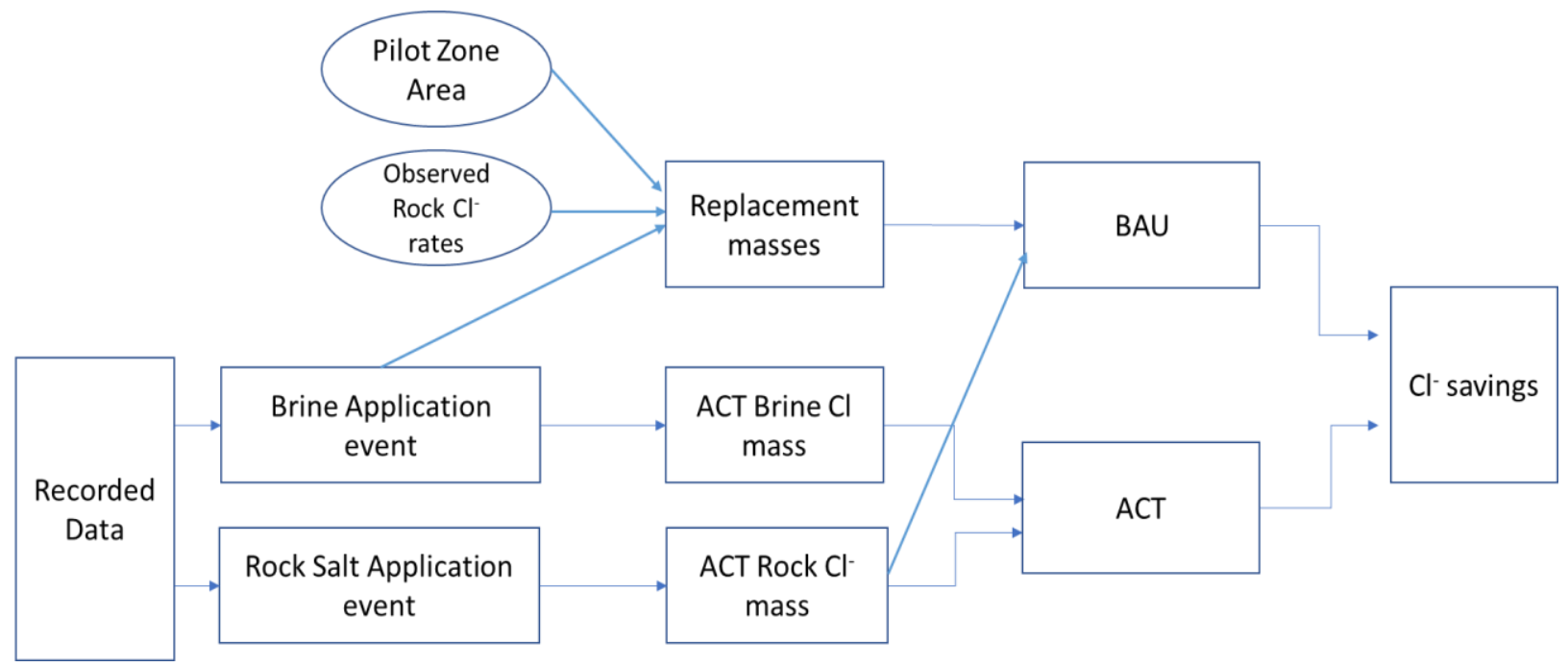

Figure 2. Workflow for the estimation of $\mathrm{Cl}^{-}$savings over observed salting events.

Rock salt application rates from all test areas were used in the creation of the replacement masses, rather than using rock salt application rates observed within the same test area as the brine event being replaced. This was due to the limited amount of data available, as some weather categories did not contain enough records to provide a robust representation of rock salt application rates. In future years when more data is available, replacement masses should be generated from rates observed within the same brine zone as those being replaced. However, as there was very little change in $\mathrm{Cl}^{-}$application rates between zones, this is not expected to cause significant error in the material savings estimations.

\subsection{Scaling Chloride Reductions to Whole 2018/19 Salting Season at Ryerson}

To estimate the $\mathrm{Cl}^{-}$savings that occurred over the entire 2018/19 winter season, an $\mathrm{ACT} \mathrm{Cl}^{-}$mass value and a BAU Cl' mass were estimated for the entire 2018/19 winter season. This was done by identifying likely brine and rock salt application events that occurred outside of the recording period, and subsequently assigning and $\mathrm{CCl}^{-}$application rate to each event based on the events weather characteristics. This enabled the creation of the 2018/19 winter season ACT and BAU $\mathrm{Cl}^{-}$masses, and the estimation of 2018/19 winter season $\mathrm{Cl}^{-}$savings. This was done with both the weather specific and nonweather specific replacement masses to generate the weather specific and non-weather specific $\mathrm{Cl}^{-}$ reduction estimations. 
Canadian Historic Climate Database records from the Pearson International Airport Weather Station (Government of Canada, 2019) were queried to identify probable brine and rock salt application events that occurred during the 2018/19 winter season. The probable brine application events were defined based on Ryerson Maintenance staff operating procedure discussed in 4.1. Therefore, brine events were defined as any event with no rainfall and between 0.2 and $3 \mathrm{~cm}$ of snow accumulation. Rock salt application events were defined as any event with above $3 \mathrm{~cm}$ snow accumulation, any event with above $0.1 \mathrm{~mm}$ of rainfall, or any event with snow accumulation above $0.2 \mathrm{~cm}$ and rain above $0.1 \mathrm{~mm}$. The classification of weather records based on the maintenance staff operating procedures was utilized even though two observed brine application events in 2018/19 occurred during conditions which fell outside of this procedure. These discrepancies are likely because maintenance activities are planned using forecasted weather data. As forecasted and observed weather conditions will inherently not be identical, there will be cases when the team used brine during conditions that would normally call for rock salt, and vise versa. Therefore, by ignoring these discrepancies, the estimates produced by this analysis should be referred to as the $\mathrm{Cl}^{-}$savings that could occur under ideal or optimal brine usage.

To generate the brine portion of the $\mathrm{ACT} \mathrm{Cl}^{-}$mass values, each identified brine event was matched with the average brine application rate of the three brine application events observed during environmental conditions adhering to Ryerson's Maintenance team's brine operating procedures. These values were then multiplied by the total area of the pilot zones to generate the brine $\mathrm{ACT} \mathrm{Cl}^{-}$masses.

Brine ACT Cl- mass $(\mathrm{Kg})=\left(\right.$ Number Brine Events) (Average Brine Application Rate $\left.\left(\mathrm{Kg} \mathrm{Cl} / \mathrm{m}^{2}\right)\right)$ (Pilot Zone Area $\left(\mathrm{m}^{2}\right)$ )

To generate the Rock Salt portion of the ACT mass value, the identified rock events were classified into the weather categories described in 4.32. However, as several classification groups did not possess a rock salt application event observed during the pilot project, these categories needed to be amalgamated. For example, there were no "Light Snow" events observed during the pilot project. Therefore, an observed rock application rate could not be matched to a "Light Snow" event identified from the historic data. To be able to match a rock salt application rate to an identified "Light Snow" event, the light snow and moderate snow categories were amalgamated. The amalgamated classification system can be seen in Table 2 . The identified rock salt events were then assigned the average rock salt $\mathrm{Cl}^{-}$application rate from the observed rock salt application events in 2018/19 which fell 
into the same weather classification category. These application rates were then multiplied by the total area of the pilot zones.

Rock ACT Cl- mass $(\mathrm{Kg})=\sum$ (Rock Salt Event) (Corresponding Rock Salt Application Rate $\left.\left(\mathrm{Kg} \mathrm{Cl} / \mathrm{m}^{2}\right)\right)$ (Pilot Zone Area $\left.\left(\mathrm{m}^{2}\right)\right)$ Eq. (2)

The sum of these values were added to the brine $\mathrm{Cl}^{-}$ACT mass to produce the 2018/19 winter season ACT $\mathrm{Cl}^{-}$mass value.

$\mathrm{ACT} \mathrm{Cl}^{-}$mass $(\mathrm{Kg})=$ Brine $\mathrm{ACT} \mathrm{Cl}^{-}$mass $(\mathrm{Kg})+$ Rock $\mathrm{ACT} \mathrm{Cl}^{-}$mass $(\mathrm{Kg})$

Eq. (3)

Table 2. Amalgamated weather classification system and number of events observed during the 2018/19 pilot study.

\begin{tabular}{|l|l|l|}
\hline Classification & Observed Rock Event & Criteria \\
\hline Snow & 1 & $>3 \mathrm{~cm}$ snow accumulation \\
\hline Light rain & 1 & $0.1-0.9$ mm rain \\
\hline Rain & 1 & $>0.9$ mm of rain \\
\hline Light Snow Rain & 1 & $\leq 1.9 \mathrm{~cm}$ snow, $>0.1 \mathrm{~mm}$ rain \\
\hline Moderate to very heavy snow rain & 1 & $>1.9 \mathrm{~cm}$ snow, $>0.1 \mathrm{~mm}$ rain \\
\hline
\end{tabular}

The $2018 / 19$ non- weather specific winter replacement masses were then calculated by multiplying the total number of identified brine events by the total average rock $\mathrm{Cl}^{-}$application rate, and the total area of the pilot zones. This was also done utilizing the average rock $\mathrm{Cl}^{-}$application rate derived from the rock salt event which occurred during typical brining conditions (i.e., snowfall $(<3 \mathrm{~cm}))$ to generate the weather specific replacement mass.

Non-Weather Specific Cl- Replacement Mass $(\mathrm{Kg})=\left(\right.$ Number Brine Events) $\left(\right.$ Total Average Rock Salt Application Rate $\left.\left(\mathrm{Kg} \mathrm{Cl} / \mathrm{m}^{2}\right)\right)$ (Pilot Zone Area $\left(\mathrm{m}^{2}\right)$ )

Eq. (4) 
Weather Specific Cl- Replacement Mass (Kg) = (Number Brine Events) (Weather Specific Average Rock Salt Application Rate (Kg $\left.\mathrm{Cl}^{-} / \mathrm{m}^{2}\right)$ ) (Pilot Zone Area $\left(\mathrm{m}^{2}\right)$ )

Eq. (5)

These values were then used to generate the Non- Weather Specific BAU and Weather Specific BAU. The ACT value was subtracted from the BAU values to produce the weather specific and non- weather specific 2018/19 winter season Ryerson $\mathrm{Cl}^{-}$reductions estimations (Figure 3).

Weather Specific BAU Cl- mass $(\mathrm{Kg})=$ Weather Specific $\mathrm{Cl}^{-}$Replacement Mass + Rock $\mathrm{ACT} \mathrm{Cl}^{-}$mass $(\mathrm{Kg})$

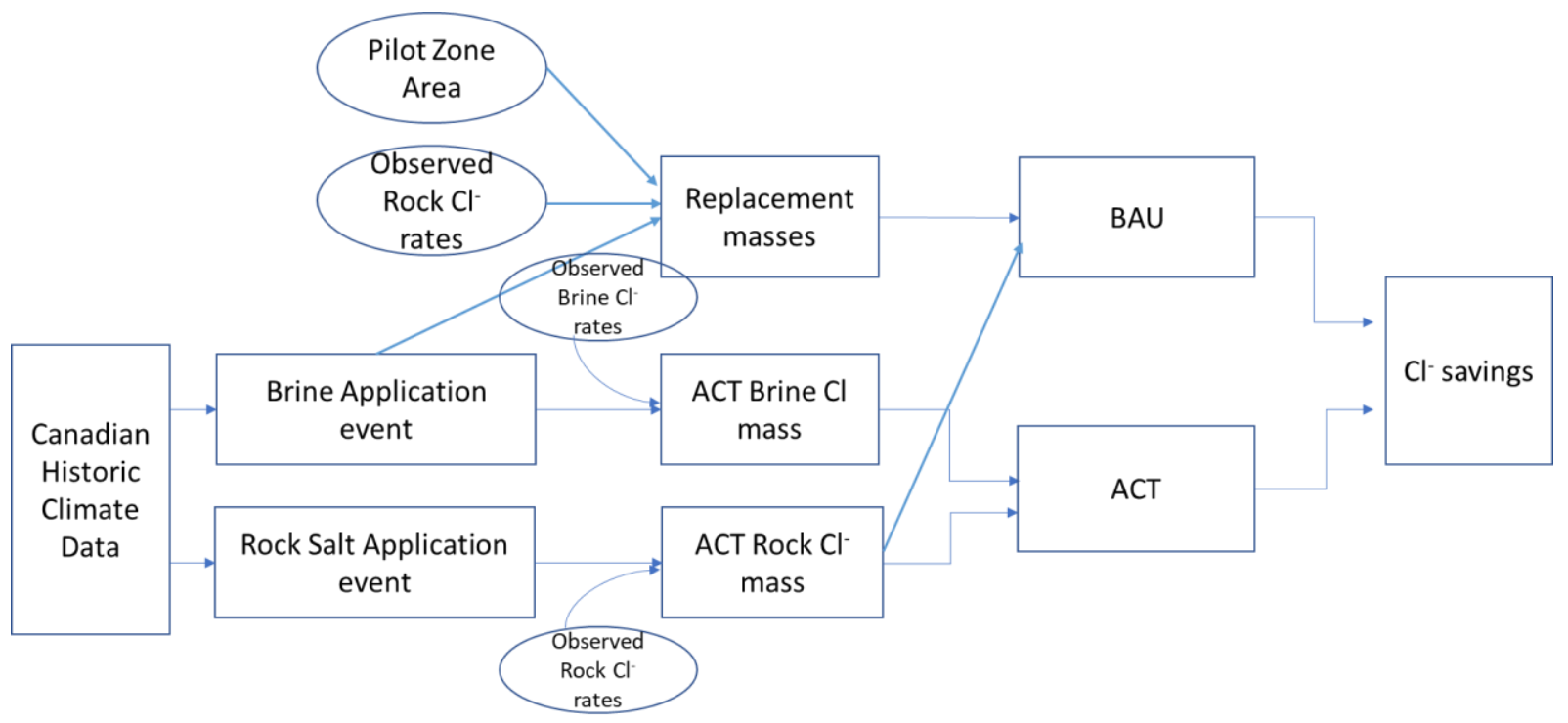

Figure 3. Workflow for the $\mathrm{Cl}^{-}$savings estimation for entire 2018/19 winter season.

Additionally, it was previously mentioned that several winter storm events observed during the pilot project required two salting applications. However, the justifications for the multiple applications were not given, and therefore it was difficult to predict which historic winter storm events would have required multiple salt application. We therefore assumed that each identified winter storm event only required a single salting. 


\subsection{Estimation of Reduction in Chloride Inputs and Material Cost if DLA Use was Expanded to Ryerson,}

Metrolinx Go Stations, King Streetcar Stops and Green P Parking Lots within the City of Toronto The procedures used in section 4.4 were modified to allow for the estimation of the total $2018 / 19 \mathrm{Cl}^{-}$ savings that could have occurred if brine was used on all areas of Ryerson campus, and for the case study expansion scenarios for the 2018/19 winter season. This was done by simply replacing the area value used in the ACT and BAU calculations in section 4.4 with the total area of Ryerson campus, and subsequently with the total areas of the expansion case studies. These BAU and ACT estimations were then used to generate the various $\mathrm{Cl}^{-}$savings estimations.

\subsection{Expansion Zones Area Calculation}

\section{i. Ryerson Campus}

The 2018 Ryerson campus site map was obtained from campus facilities and was subsequently digitized. This map describes detailed information about all campus property, including the locations of walkways, curb lines, sidewalks, roads etc. The 2018 City of Toronto Property Map Data (City of Toronto Works and Emergency Services, 2018) was also added to the GIS. This data possesses current locations of curb lines, sidewalks, and property boundaries of all areas of Toronto. Using these two data sources, a shapefile was created cataloguing all

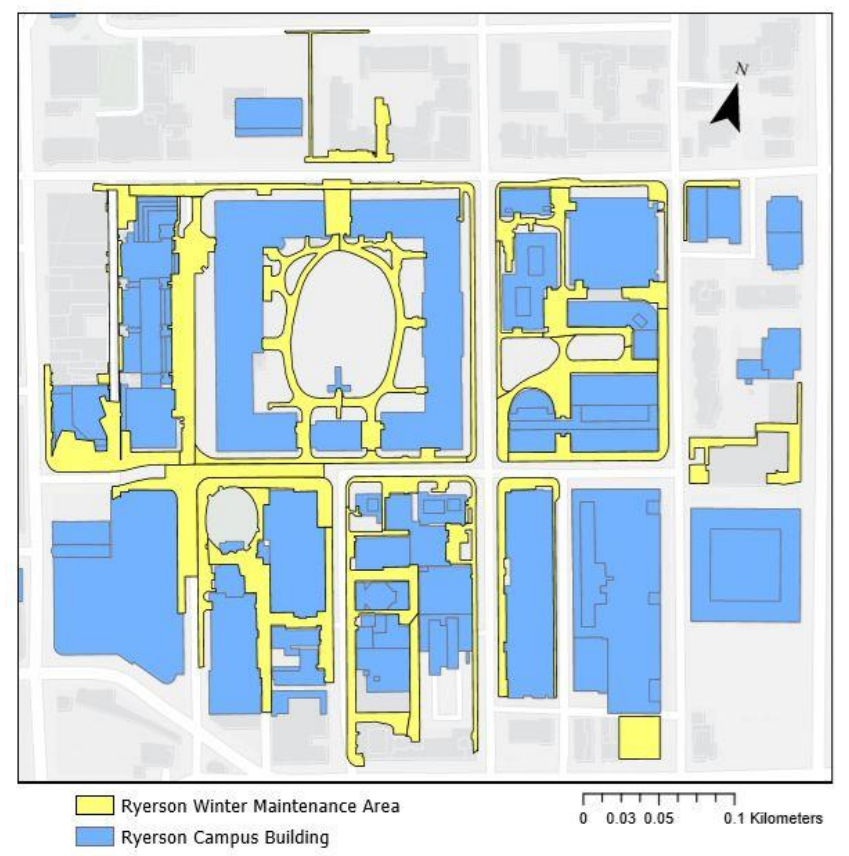

Figure 4. Impermeable Surfaces under the jurisdiction of Ryerson's Facilities Maintenance Team. impermeable surfaces under the jurisdiction of Ryerson's maintenance team (Figure 4). Finally, Ryerson's maintenance manager was consulted to verify all areas that fall under the jurisdiction of the Ryerson maintenance team were accounted for. 


\section{ii. Metrolinx Go Stations}

To isolate the impermeable surfaces associated with each Metrolinx Go Station along the East and West Lakeshore line within the Metropolitan of Toronto (Figure 5), the City of Toronto 2018 Orthographic Imagery data (City of Toronto Survey and Mapping Services, 2018) was utilized in conjunction with the 2018 City of Toronto Property Map Data property boundaries (City of Toronto Works and Emergency Services, 2018) to determine which property polygon

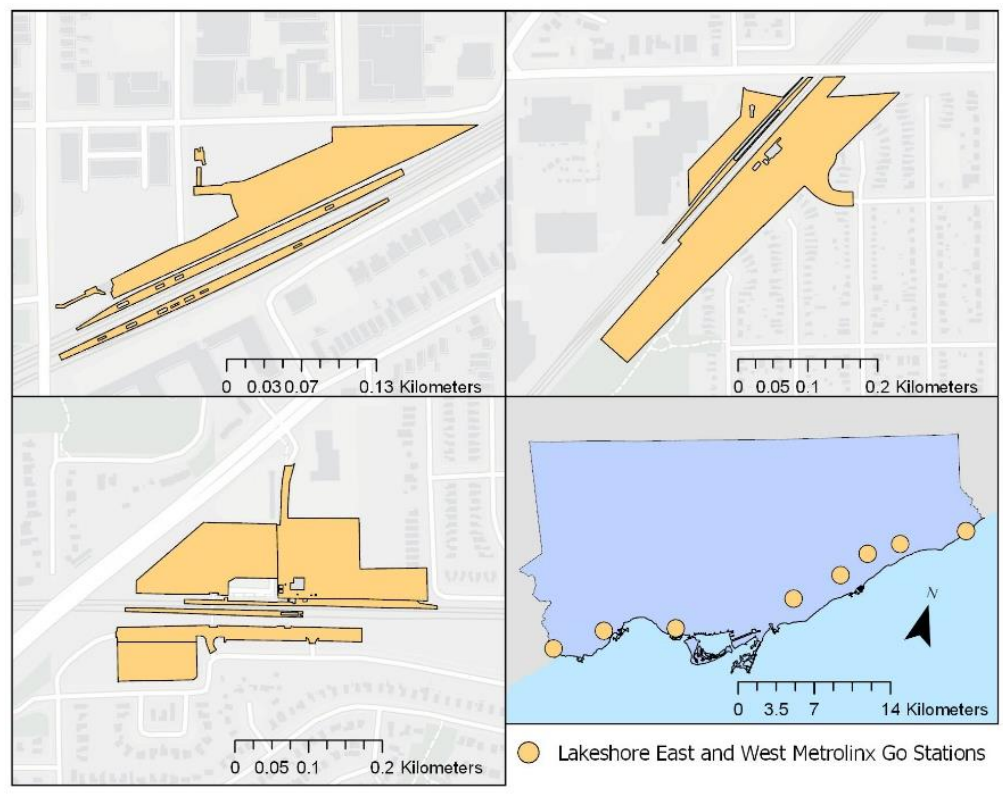

Figure 5. Mimico Station (Top Left), Scarborough Station (Top Right), Guildwood Station (Bottom Left), and the locations of all Lakeshore East and West Metrolinx Go Stations within the Metropolitan of Toronto.

belonged to each station. The curb line, sidewalks, and pathways information from the 2018 Property Map dataset was then used to isolate the areas that most probably require winter salting. These included uncovered platform areas, walkways, and designated station parking lots on Metrolinx property. Union Station was not considered in this analysis as the majority of the station is indoors.

\section{iii. King Street Streetcar Stops}

Waiting areas at streetcar stops within the City of Toronto vary from explicitly designated areas, to simple signs posted on sidewalks (Figure 6.). To quantify the total waiting area of all the streetcar stops along the King Street 504 streetcar line, an average waiting area of $8.82 \mathrm{~m}^{2}$ was assumed for each stop. This corresponds to the total area of two sidewalk slabs (City of Toronto, 2017). This area value was multiplied by the total number of streetcar stops on this route to generate the total

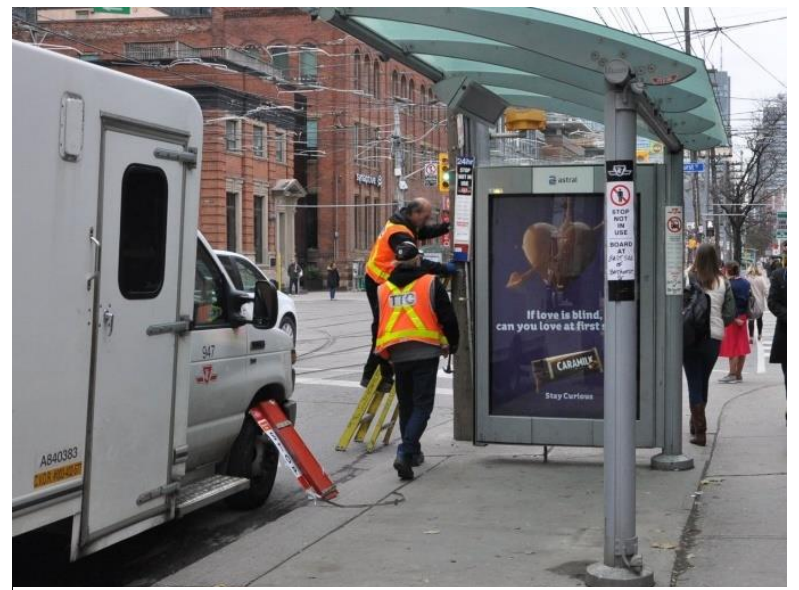

Figure 6. Example of King Street Bus/Streetcar Transit Stop (Urban Toronto, 2017). area of all streetcar stops 


\section{iv. Green P Parking Lots}

The City of Toronto Green P parking lot dataset describes the location, capacity, and characteristics of every public "Green P" parking lot in the City of Toronto (Toronto Parking Authority, 2019). The point location of each Green $P$ parking lot was used in an overlay analysis with the 2018 City of Toronto Property Map Data property boundary shapefile (City of Toronto Works and Emergency Services, 2018) to determine which property polygon contained each parking lot point. Only outdoor parking lots were considered. Subsequently, the 2018 City of Toronto Property map information was used to isolate all parking lot area on Green P property

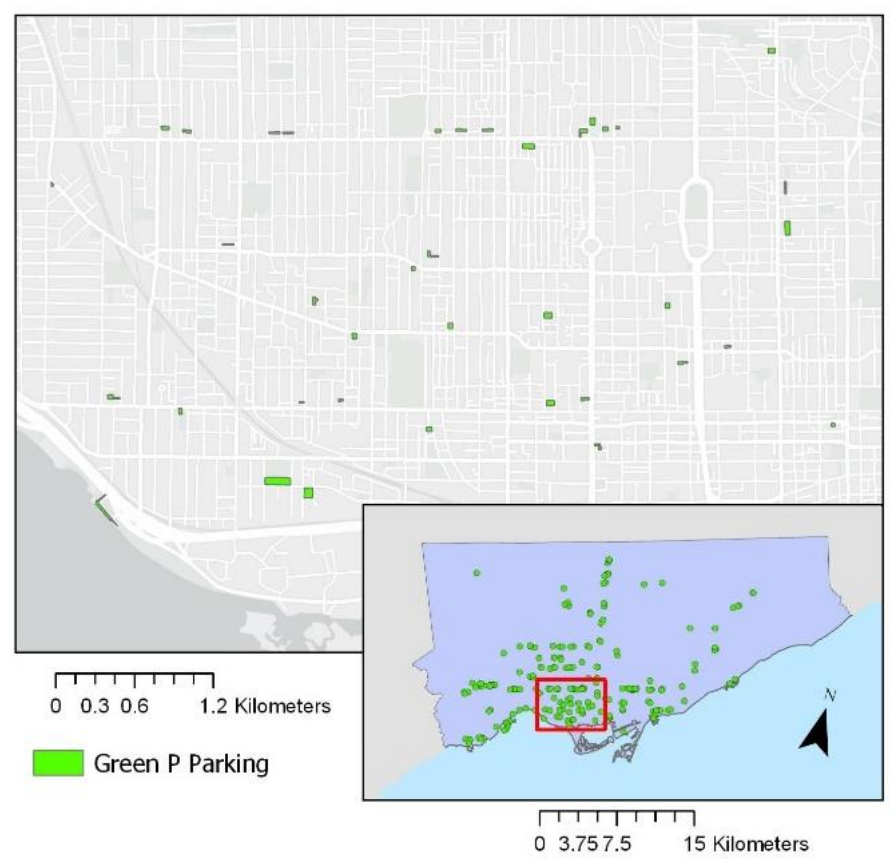

Figure 7. Green P parking lots within the Metropolitan of Toronto (Figure 7).

\subsection{Scaling Chloride Reductions to Case Studies}

To provide an estimate of the potential material and cost savings experienced from the hypothetical adoption of DLA throughout Ryerson and the case study areas during the 2018/19 winter season, the historic 2018/19 brine and rock salt events identified in section 4.4 and their associated brine and or rock application rates were used to estimate an ACT and a BAU scenario for each expansion case study. The methods used to compute the BAU and $A C T \mathrm{Cl}^{-}$estimations were identical to section 4.4, with the exception that the $\mathrm{NaCl}$ and $\mathrm{Cl}^{-}$mass calculation for each case study scenario considered the entire area of that expansion case study, rather than the Ryerson pilot zones. The $\mathrm{NaCl}$ savings were then used to estimate monetary savings for each expansion scenario using the average price of $\$ 5.18$ per $20 \mathrm{~kg}$ bag of $\mathrm{NaCl}$ (D. Batko, pers. comm.).

It is very important to note that the savings estimations for the TTC, Green P and Metrolinx are based on observed road salt and brine application rates used by the Ryerson facilities team. The standard rates utilized by these organizations and the Ryerson facilities team likely differ, and any major difference will result in discrepancies between the predicted $\mathrm{Cl}^{-}$savings values, and those that would occur from the actual adoption of DLA by these organizations. Therefore, the estimated $\mathrm{Cl}^{-}$savings produced by this 
analysis should be considered as example of the savings that could occur if the case study organization utilized similar winter maintenance practices as Ryerson.

\subsection{Sampling Error Calculation}

For each $\mathrm{Cl}^{-}$reduction estimation, the associated error was calculated. This was done by propagating the error associated with each mean event $\mathrm{Cl}^{-}$application rate through any and all calculations using these rates. For any operation involving the addition or subtraction of an estimated $\mathrm{Cl}^{-}$mass, for example the subtraction of the ACT from the BAU, the standard error associated with each $\mathrm{Cl}^{-}$mass estimate was summed in quadrate. Additionally, for any operation involving the multiplication of an estimated $\mathrm{Cl}^{-}$ mass by a constant, such as an area value, the standard error of the $\mathrm{Cl}^{-}$mass estimate was also multiplied by that constant.

\subsection{Historical analysis of DLA incorporation}

The $2018 / 19$ winter was characterized by abnormally large snowfalls and cold temperatures. These conditions are not optimal for DLA, and surely reduced its utility in 2018/19. A more moderate winter with more ideal weather conditions for DLA could have seen more frequent use of brine, and therefore higher $\mathrm{NaCl}$ and $\mathrm{Cl}^{-}$reductions. To evaluate whether the $\mathrm{Cl}^{-}$reductions experienced during the 2018/19 winter season were representative of typical Toronto winters, and to quantify the typical $\mathrm{Cl}^{-}$savings that could be experienced over time, the historic climate data was utilized to assess the winter season characteristics and $\mathrm{Cl}^{-}$reduction values for each winter season between 1938 and 2018. Each year was queried for likely rock and brine application events utilizing the same methods employed in section 4.52. These records were used to generate the total number of application days, the proportion of those events which required brine (according to criteria outlined in section 4.1), and the percent $\mathrm{Cl}^{-}$reduction as a result of the use of DLA for each winter season. These values were then used to estimate the benefit of DLA in Toronto for the average winter conditions.

Climate change has and will continue to alter the climatic conditions in Canada. These changes may or may not impact the number of brine events experienced annually and may therefore have implications for the utility of DLA use in the future. To assess the impact of these changes, the historic climate data was also utilized to assess whether the number of events which qualify for a brine application has changed over time. The total number of brine events, and the proportion of events that required brine were computed and compared over time. 


\section{Results}

\subsection{Brine Application Rates}

The brine $\mathrm{Cl}^{-}$application rates observed in 2018/19 were generally much lower than the observed rock salt application rates, as the brine was found to have a mean and \pm standard error $\mathrm{Cl}^{-}$application rate of $0.014 \pm 0.001 \mathrm{~kg} \mathrm{Cl} / \mathrm{m}^{2}$, while rock salt had a mean and \pm standard error of $0.0029 \pm 0.003 \mathrm{~kg} \mathrm{Cl} / \mathrm{m}^{2}$. The Shapiro- Wilks test of normality indicated that the mean rock and brine event $\mathrm{Cl}^{-}$application rates were normal $(P=0.04)$, and the Levene's Test for equality of variances indicated homogeneity of variance. It was found that the two application methods had significantly different $\mathrm{Cl}^{-}$application rates, with brine having significantly lower rates $(T(8)=-4.083, P=0.004)$. Weather was also found to have a predictable and expected effect on $\mathrm{Cl}^{-}$application rates. Application rates were consistently lower in conditions with less snow accumulation and the presence of rain typically increased the $\mathrm{Cl}^{-}$requirements (Table 3).

Table 3. Mean $\mathrm{Cl}^{-}$application rate of brine and rock salt application events grouped by weather categories.

\begin{tabular}{|l|l|l|}
\hline Classification & Brine $\mathrm{Cl}^{-}$Application Rate $\left(\mathrm{Kg} \mathrm{Cl}^{-} / \mathbf{~ m}^{2}\right)$ & Rock Salt Cl Application $\mathrm{Rate}\left(\mathrm{Kg} \mathrm{Cl}^{-} / \mathrm{m}^{2}\right)$ \\
\hline Snow & 0.011 & 0.027 \\
\hline Rain & 0.017 & 0.025 \\
\hline Light Snow - Rain & & 0.033 \\
\hline Moderate Snow - Rain & 0.020 & 0.036 \\
\hline
\end{tabular}

The interzonal variation of brine and rock $\mathrm{Cl}^{-}$application rates were found to be insignificant. There was found to be overlap between of the majority of the medians, and as there was overlap between the spread of all box plots this suggest that no one zone received significantly higher or lower $\mathrm{Cl}^{-}$application rates (Figure 8).

The brine $\mathrm{Cl}^{-}$application rates observed at Ryerson in 2018/19 were found to be larger than the rates utilized or recommended by organizations in Toronto, or within Canada. The City of Toronto states that its standard application rate of $0.0056 \mathrm{~kg} \mathrm{Cl} / \mathrm{m}^{2}$ is utilized during brine applications (City of Toronto, 2016). The City of Winnipeg utilizes a brine application rate of $0.0064 \mathrm{~kg} \mathrm{Cl} / \mathrm{m}^{2}$ (Transportation Association of Canada, 2013). Several advocacy groups such as the Salt Vulnerable Areas Working Group and Clear Roads recommend rates between 0.0045 and $0.0105 \mathrm{Kg} \mathrm{Cl}^{-} / \mathrm{m}^{2}$ (Crewe \& Gowda, 2018; Nixon 
\& DeVries, 2015). Additionally, in 2014 Hossain determined that as little as $0.0021 \mathrm{~kg} \mathrm{Cl}^{-} / \mathrm{m}^{2}$ is required to achieve optimal levels of service (S. M. K. Hossain, 2014)

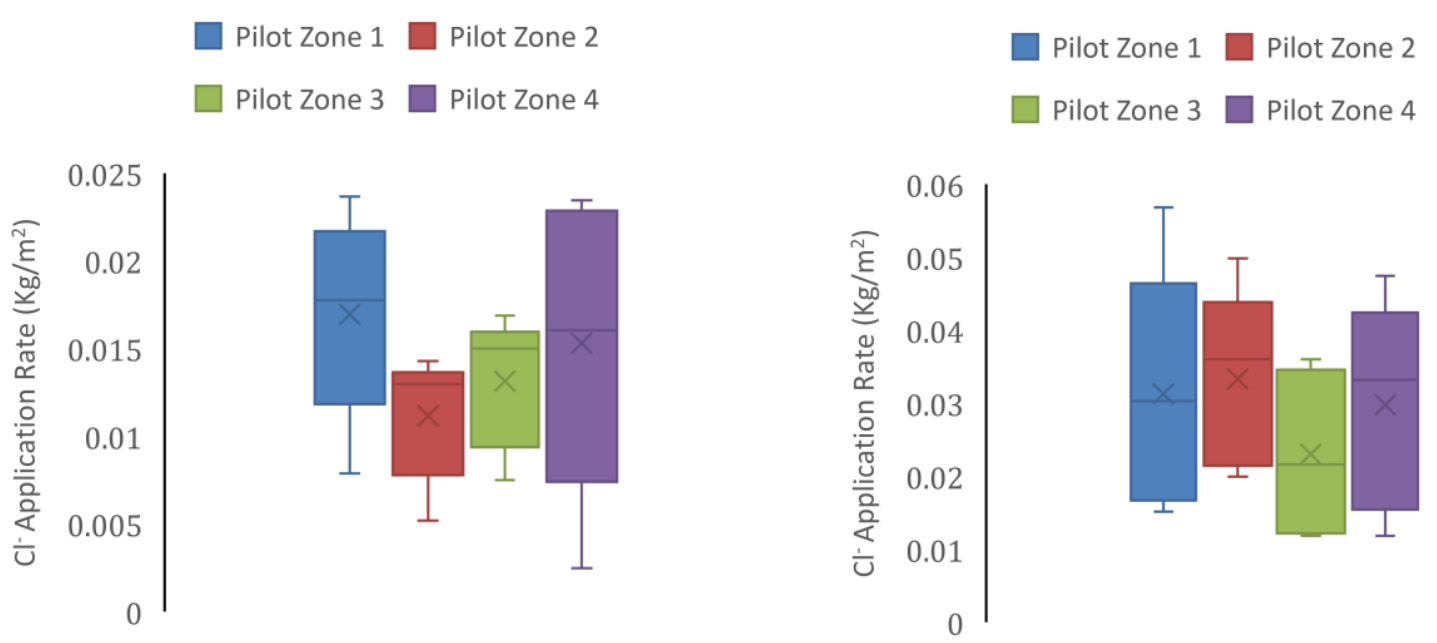

Figure 8. Interzonal Variation in Brine (left) and Rock Salt (right) $\mathrm{Cl}^{-}$application rates.

Additionally, the rock salt application rates observed at Ryerson were found to be within the accepted range of rock salt application recommended by organizations and acedemic literature in Canada. The Transportation Association of Canada recomends rock salt application rates that correspond to $\mathrm{Cl}^{-}$ application rates between 0.015 and $0.024 \mathrm{Cl}^{-} \mathrm{kg} / \mathrm{m}^{2}$ (Transportation Association of Canada, 2013). The City of Toronto utilized rates beteen 0.014 and $0.037 \mathrm{~kg} / \mathrm{m}^{2}$ (City of Toronto, 2016). Additionally, a study at the University of Waterloo found that in terms of performance, a rock salt application rate that applies $0.015 \mathrm{Cl}^{-} \mathrm{kg} / \mathrm{m}^{2}$ was optimal (K. Hossain \& Fu, 2016). Although select observed rock salt application rates were found to be larger than these recomeneded rates, the mean Ryerson rock salt application rate does fall within these recomedned rates (Figure 8).

\subsection{Estimation of Chloride Reduction at Pilot Zones Ryerson 2018/19}

The results of the weather specific analysis suggest that approximately $544.33 \pm 82.26 \mathrm{~kg}$ of $\mathrm{Cl}^{-}$were diverted from the environment as a result of the use of DLA at Ryerson over the 10 recorded salting events (Figure 9). This corresponds to a total mass of $879.26 \pm 132.88 \mathrm{~kg}$ of NaCl, a total financial savings of $\$ 232.89 \pm 35.12$ and a total overall reduction of $\mathrm{Cl}^{-}$output of $23.53 \pm 3.56 \%$ (relative to BAU levels). The non- weather specific analysis suggests slightly higher saving values at $636.34 \mathrm{~kg} \pm 122.39$ of $\mathrm{Cl}^{-}$, $1048.93 \pm 201.75 \mathrm{~kg}$ of $\mathrm{NaCl}$, a total financial savings of $\$ 271.67 \pm 52.254$, and a total overall $\mathrm{Cl}^{-}$ reduction of $26.46 \pm 5.09 \%$. 


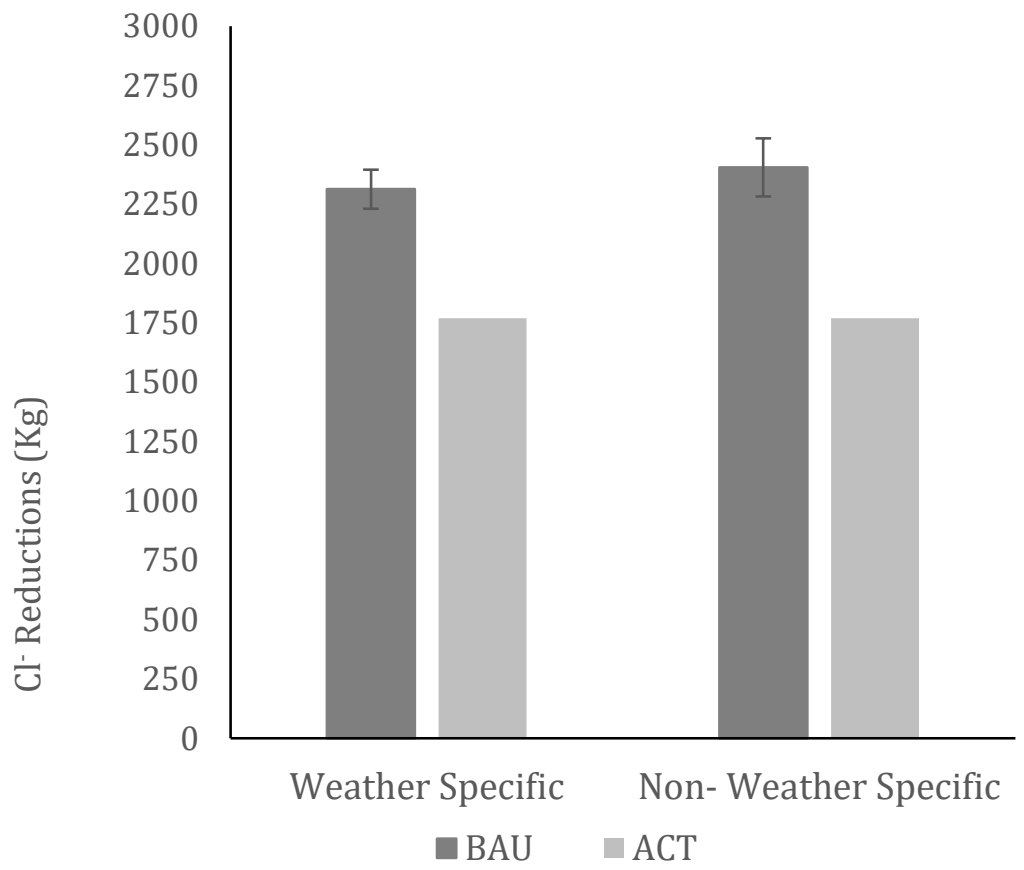

Figure 10. Estimated Weather Specific and Non- Weather Specific $\mathrm{Cl}^{-}$reductions that occurred during 10 observed salting events.

The querying of the 2018/19 historic climate data identified 20 likely brine application events, and 14 likely rock salt application events. The chloride reduction estimation utilizing the weather specific replacement masses indicated that approximately $2589.06 \pm 318.49 \mathrm{~kg}$ of $\mathrm{Cl}^{-}$was diverted at Ryerson over the 2018/19 winter season, a total $\mathrm{Cl}^{-}$reduction of $37.5 \pm 4.61 \%$ (Figure 10). This corresponds to a

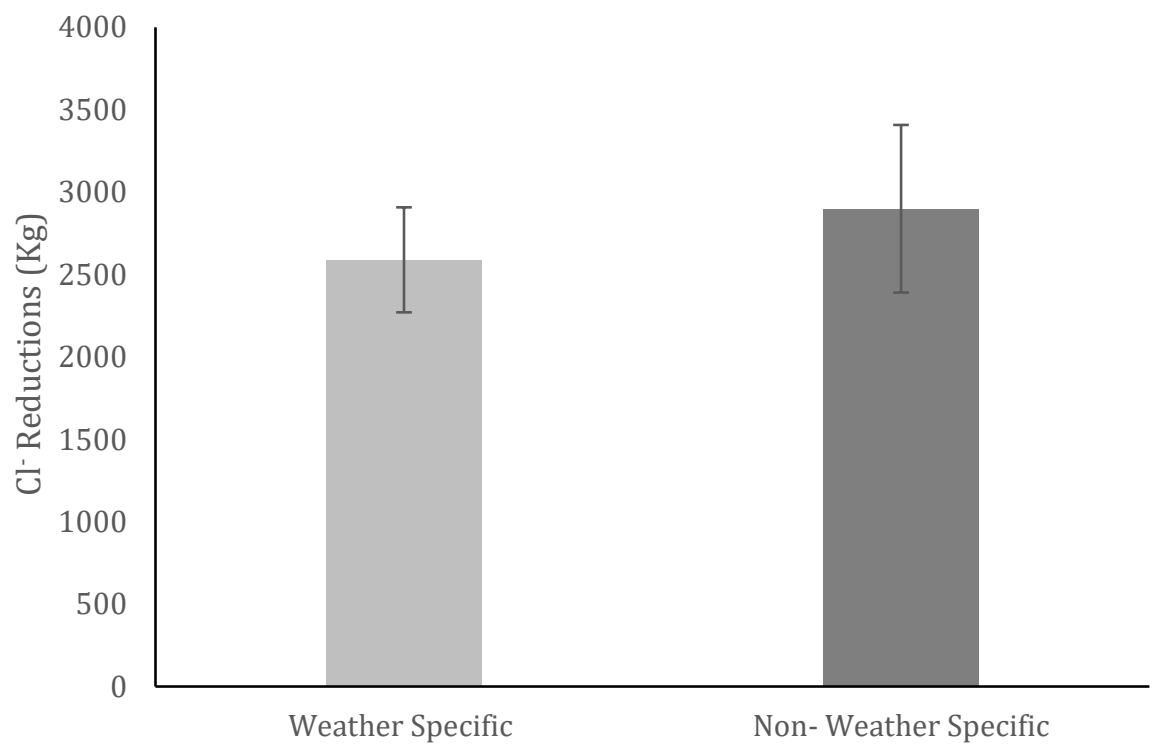

Figure 9. Weather and Non- Weather Specific Cl- reduction estimations for DLA use at Ryerson Pilot Zones throughout 2018/19 winter season. 
total $\mathrm{NaCl}$ reduction of $4267.76 \pm 525 \mathrm{~kg}$ and a total material costs savings of $\$ 1105.04 \pm 135.94$. The non- weather specific $\mathrm{Cl}^{-}$saving estimation resulted in a $\mathrm{Cl}^{-}$reduction of $2899.06 \pm 508.55 \mathrm{~kg}$ and a NaCl reduction of $4778.76 \pm 838.29 \mathrm{~kg}$. This represents a $40.14 \pm 7.04 \%$ reduction in $\mathrm{Cl}^{-}$use and material cost savings of $\$ 1237.36 \pm 217.01$. The error associated with these estimations were found to be fairly large, as these error values varried from $12 \%$ to $17 \%$.

\subsection{Estimation of Chloride Reduction due to Brine Expansion to all Ryerson Campus and Case Studies}

For all areas of Ryerson campus, the weather specific analysis found reductions of $9930.84 \pm 1221.67 \mathrm{~kg}$ of $\mathrm{Cl}^{-}, 16369.81 \pm 2013.77 \mathrm{~kg}$ of $\mathrm{NaCl}$ and $\$ 4238.60 \pm 521.43$. The non- weather specific analysis estimated reductions of $11119.92 \pm 1950.67 \mathrm{~kg}$ of Cl$, 18,329.85 \mathrm{~kg}$ of $\mathrm{NaCl}$ and $\$ 4746.12$ material cost savings (Figure 11). The savings estimation experienced by Green P and Metrolinx were much larger than that of Ryerson, as the weather specific analysis estimated $\mathrm{Cl}^{-}$reductions of 254,785.80 $\pm 31,343.09$ $\mathrm{kg}$ and 63,199.25 $\pm 774.61 \mathrm{~kg}$ respectively, and the non- weather specific analysis estimated $\mathrm{Cl}^{-}$ reductions of $285,292.70 \pm 50046.06 \mathrm{~kg}$ and $67,748.78 \pm 11,884.49 \mathrm{~kg}$ respectively (Figure 11). These masses correspond to a material cost savings of $\$ 108,745.80 \pm 13,377.63-\$ 121,766.50 \pm 21,360.29$ for
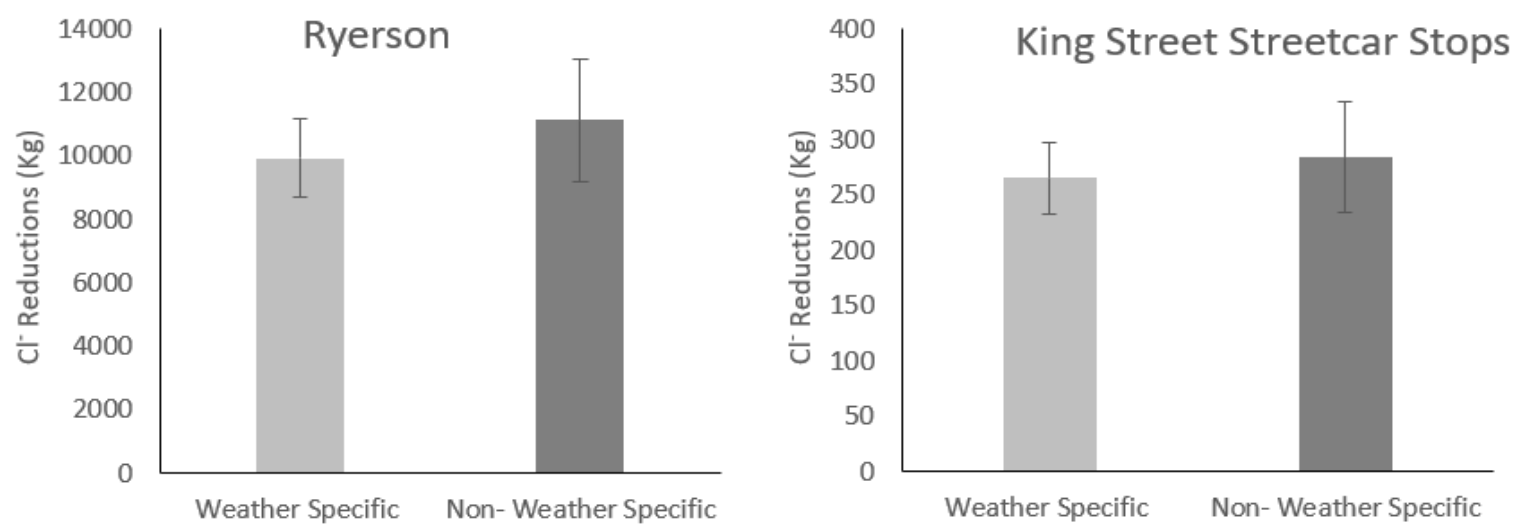

Figure
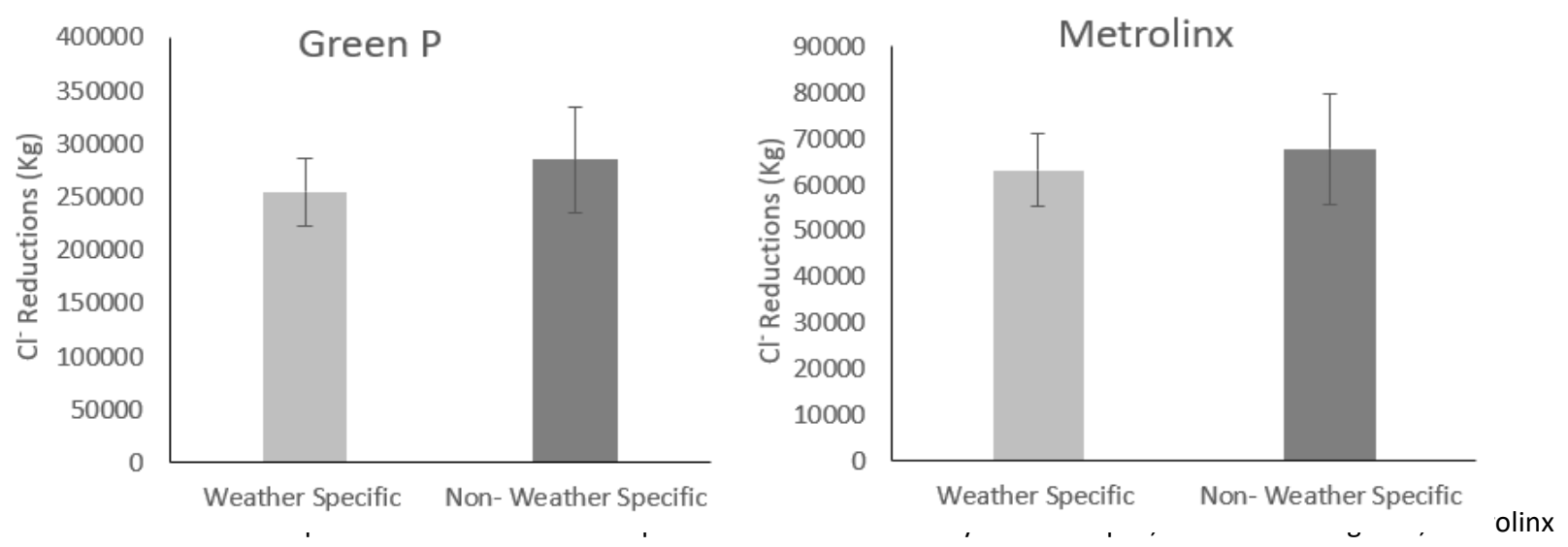

Go Stations, and TTC King Street Transit Stops 
Green $\mathrm{P}$ and $\$ 26,974.23 \pm 3318.30-\$ 28,916 \pm 5072.45$ for Metrolinx. The saving estimations for the King Street Streetcar case study produced consider ably smaller saving estimations, as reductions of 265 $\pm 32.61-284.15 \pm 49.85 \mathrm{~kg}$ of $\mathrm{Cl}^{-}$were found (Figure 11). However, similar to section 5.2 , the error associated with these $\mathrm{Cl}^{-}$estimation values were found to be large.

\subsection{Historical Analysis of DLA Incorporation}

Between the winters of 1938 and 2018, the mean number of events that met de-icing standards per winter season was found to be 34.9 ( $\min 18$, $\max 56)$. Of those events, on average $61 \%(\min 31.7 \%$, max $88.5 \%$ ) 'qualified' for brining. The winter of 2018/19 had 37 events that met de-icing standards and is therefore slightly above the average. Of those events, a below average 54 \% 'qualified' for brine applications. As a result, there was an above average proportion of rock salt applications in 2018/19 when compared to previous years.

Table 4. Summary Statistics of Historic Climate Data Analysis

\begin{tabular}{|l|l|l|l|l|}
\hline & $\begin{array}{l}\text { Number of Brine } \\
\text { Application }\end{array}$ & $\begin{array}{l}\text { Number of Rock Salt } \\
\text { Applications }\end{array}$ & $\begin{array}{l}\text { Number of Salting } \\
\text { Events }\end{array}$ & $\begin{array}{l}\text { Percent Brine } \\
\text { Applications (\%) }\end{array}$ \\
\hline Mean & 21.4 & 13.5 & 34.9 & 61.4 \\
\hline Min & 11.0 & 3.0 & 18.0 & 31.7 \\
\hline Max & 39.0 & 28.0 & 56.0 & 88.5 \\
\hline $2018 / 19$ & 20.0 & 17.0 & 37.0 & 54.1 \\
\hline
\end{tabular}

The assessment of the number of brine events per year shows a slight increase in the total proportion of events that required brine between 1938 and 2018 (Figure 12). This increase suggests that the utility of brine has increased over that same time period.

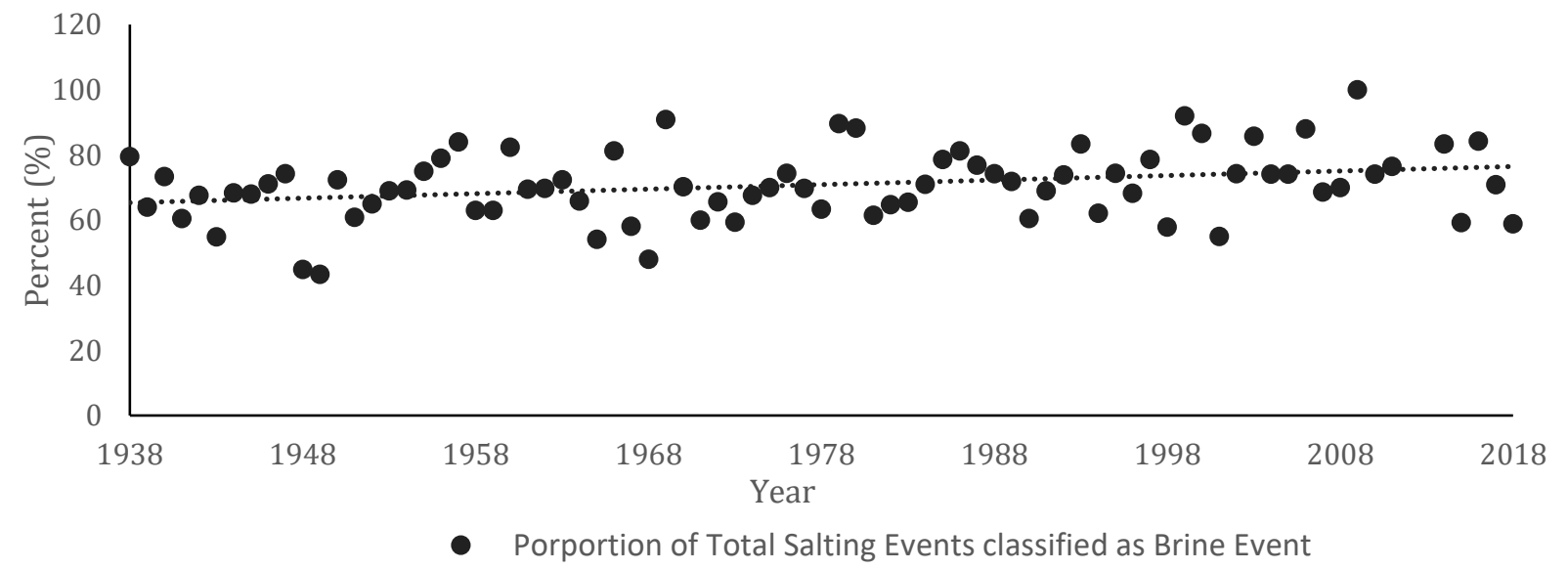

Figure 12. Increase in proportion of total salting events requiring brine between 1938 and 2018 


\section{Discussion}

\subsection{Effectiveness of DLA at Reducing Chloride Inputs to the Environment from Ryerson University}

The statistical analysis of the brine and rock salt application rates observed during the 2018/19 Ryerson Road Salt Reduction pilot showed that DLA required significantly less $\mathrm{Cl}^{-}$than conventional rock salt. This on its own suggests that Ryerson did experience $\mathrm{Cl}^{-}$reductions due to the incorporation of DLA into its winter maintenance program. Additionally, although the results were accompanied by large error

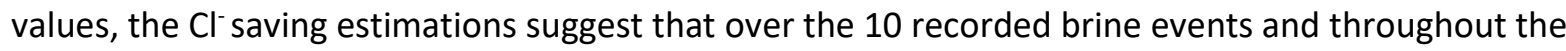
2018/19 winter season, DLA use did result in significant $\mathrm{Cl}^{-}$reductions. These results do suggest that the incorporation of DLA was an effective approach for reducing $\mathrm{Cl}^{-}$inputs to Ryerson Campus.

It was also found that the percent $\mathrm{Cl}^{-}$reduction was larger throughout the entire 2018/19 winter season than during the 10 observed salt application events. This is an interesting result and may be a result of the inclusion of the shoulder seasons into the $\mathrm{Cl}^{-}$reduction analysis for the entire 2018/19 winter season. DLA is more beneficial during the shoulder seasons (i.e., early and late winter) as these periods of time typically experience greater numbers of precipitation events with require brining (i.e., lighter snow events). The $\mathrm{Cl}^{-}$estimation for the entire 2018/19 winter season would have captured the shoulder seasons, whereas the observed salt application events were mostly recorded outside of these shoulder seasons. This conclusion is aligned with testimony from Ryerson's Maintenance team, who have stated greater $\mathrm{Cl}^{-}$savings occurred early and late in the winter season (D. Batko, pers. comm.).

The results of section 5.3 provide a strong justification for the expansion of the pilot project to all areas of campus, as the weather specific analysis estimated that this could result in significantly greater $\mathrm{Cl}^{-}$ reductions.

\subsection{Cost Savings Associated with the Use of DLA on Ryerson University Campus}

The monetary savings associated with $\mathrm{NaCl}$ reductions at Ryerson in 2018/19 were estimated at approximately $\$ 969.16$ to $\$ 1241.88$. Additionally, Dan Batko, Ryerson Facilities manager estimates that the increased ease of snow removal, due to increased ease of snow removal and more effective snowfall melt, reduced labour costs by approximately 3-4 hours per precipitation event. At a labour cost of 26$59 \$$ an hour, this suggests that an additional $\$ 1560-4720$ was saved due to the use of brine at Ryerson in $2018 / 19$ (D. Batko, pers. comm.). The total cost of the brine equipment was $\$ 9976$. Therefore, even if the project is not expanded and the material cost savings remain similar to $2018 / 19$, the labour and material financial savings should cover the equipment cost in at least 4 years. This however does not take into account any degradation of the brine equipment over that period of time. 
Dan Batko also stated that the current Ryerson brine vehicle could be used on a larger area of campus, possibly up to $50 \%$ of campus or $15885.5 \mathrm{~m}^{2}$. During the pilot, the total area of the pilot zones was 8283 $\mathrm{m}^{2}$. If the area that the brine machine is responsible for was increased to $50 \%$ of campus, the total material and financial savings would nearly be doubled. This would also greatly reduce the equipment payoff period.

\subsection{Chloride Diversion and Cost Savings Associated with Case Studies}

Despite the error associated with the results, the estimation of $\mathrm{Cl}^{-}$and monetary savings that would occur from the adoption of DLA by external organizations was successful in illustrating the potential for DLA adoption by Green P and Go Metrolinx. If DLA was adopted by these two organizations, that would represent a reduction in emitted $\mathrm{Cl}^{-}$equivalent to nearly $75 \%$ of the salt usage for the municipality of Brockville, a city of nearly 22,000 . Additionally, these reductions correspond to total material cost reductions of between $\$ 108,745.80 \pm 13,377.63$ and $\$ 121,766.50 \pm 21,360.29$ for Green $P$, and between $\$ 26,974.23 \pm 3318.30$ and $\$ 28,916 \pm 5072.45$ for Metrolinx Go.

Additionally, many Metrolinx stations and Green P Parking lots analyzed in this study would be ideal for DLA adoption. Seven of the nine Go Stations, and 25 of the 214 Green P parking lots have areas above $8283 \mathrm{~m}^{2}$, the size of the Ryerson Pilot Zones. These stations could therefore each support at least one brine machine and experience similar $\mathrm{Cl}^{-}$and cost reductions than those experienced at Ryerson in 2018/19. The geographic layout Metrolinx Go Stations may also ideal for brine adoption as the areas are very localized, and the on-site facilities would likely have space for brine equipment. The 25 parking lots with areas of over $8283 \mathrm{~m}^{2}$ also represent 53.2\% of the total Green P Parking area. Therefore by adopting DLA in this relatively small number of parking areas, Green P could experience over half the estimated $\mathrm{Cl}^{-}$and cost reductions estimated by this study. These Go Stations and Green P parking lots would therefore be ideal for test or pilot projects.

The total $\mathrm{Cl}^{-}$and monetary savings estimated for the TTC king Streetcar line were less impressive due to the small total area of the king street streetcar line stops. However, anecdotal evidence suggests that BAU road salting rates at these sites is far in excess of the rates we measured on Ryerson campus, so further research is needed to more accurately estimate potential $\mathrm{Cl}^{-}$savings.

\subsection{Historical Comparison of DLA Utility}

The utility of DLA in 2018/19 in terms of proportion of weather events that required brine was below average for the typical winter season. This suggest that the relative utility of DLA was reduced in 
2018/19, and Ryerson's Facilities staff should expect to utilize DLA for a greater proportion of winter events in the coming years. Additionally, the examination of the historical analysis of DLA utility suggests that since 1938, there has been a slight rise in the number of brine events, and therefore the utility of DLA may continue to increase in the future. However, historic weather data was acquired from only one station in Toronto, and more research is needed to determine if this pattern is consistent across all geographic areas and is likely to continue with the effects of climate change.

\subsection{Limitations and Recommendations}

Although this study was able to produce estimates of the mass of $\mathrm{Cl}^{-}$that was diverted from the environment as a result of the Ryerson Road Salt Reduction Project, and the hypothetical adoption of DLA by the case study scenarios, the large uncertainties surrounding these values suggests that future research is needed to verify the results. Ryerson's Facilities team is currently planning the adoption of an electronic recording system which will allow for the recording of every brine and rock salt application event. If this program is successful, the number of observed salting events would be dramatically increased, and the uncertainties associated with the brine and rock salt applications rates could be significantly reduced. Therefore, following the 2019/20 winter season, this methodology could be used to provide valid $\mathrm{Cl}^{-}$savings estimations.

The small sample size also reduced the ability of this analysis to account for weather conditions, as several weather classification categories needed to be amalgamated. This lack of recorded events for the entire winter season also forced the use of the historic daily weather data to estimate the total savings experienced during entire 2018/19 winter season.

Although increasing the total number of observations could increase the precision of $\mathrm{Cl}^{-}$reduction estimation and eliminate the reliance on historic daily weather data, lessons learned through this analysis provide strong justification for the altering the structure of the pilot project's recording system. As previously mentioned, during the winter of 2018/19 brine and rock salt were never utilized at the same time, during the same conditions. This made it necessary to estimate the BAU values with rock salt application rates observed in different environmental conditions than the brine event being replaced. This source of error could be avoided if one or more control areas in which only rock salt were utilized was established on Ryerson campus. This would nullify the need to classify and match the application rates based on observed weather conditions as the replacement mass for each brine application event could be derived using the rock salt application rate or rates observed during the associated brine application event. This would also likely reduce the error associated with the $\mathrm{Cl}^{-}$reduction estimations as 
a single application rate would be used for the generation of the replacement masses, or if multiple control areas were established there would likely be much less variance between the rock salting applications observed during a single event than the rock salting application rates observed during different storm events that are classified as the same storm type.

Ryerson, and other pilot projects, may also be interested in the addition of a performance measure into the brine pilot project. Ryerson's facilities team does record the number of slip and falls that occur during the winter season, and there were no reported increased number of falls following the implementation of DLA use on Campus. However, as health and safety standards must be met, the performance of brine should be assessed as the pilot project continues. Assessing the performance of the brine and rock salt, such as time to bare pavement or friction coefficient, would allow the facilities team to determine if DLA is performing worse, better or to the level of rock salt. This may also allow for an assessment of optimal application rates and the impact of environmental conditions such as surface type, foot traffic, shade levels etc. This could be done by establishing different treatment areas on campus, in which the performance of various brine and rock salt application rates are assessed. Treatments of alternative de-icers and anti-icers, such as beat juice and brine mixtures, could also be established. This would however require additional coordination and sampling efforts.

Finally, as seen in section 8.1 the brine $\mathrm{Cl}^{-}$application rates utilized in the Ryerson Road salt reduction pilot project were found to be generally larger than brine $\mathrm{Cl}^{-}$application rates utilized or recommended by other organizations, municipalities, and academic researchers. This suggests that in the future, the application rates of brine to Ryerson campus could be slightly reduced to better reflect these recommended rates. This would further increase the $\mathrm{Cl}^{-}$savings experienced as a result of DLA use.

\section{Conclusion}

The widespread application of road salts for winter maintenance safety causes extensive damage to natural and urban environments. Although anecdotal evidence suggested that the Ryerson Road Salt Reduction Pilot Project, which saw the incorporation of DLA at Ryerson University, resulted in significant $\mathrm{Cl}^{-}$reduction, this study empirically quantified those savings and investigated whether the savings experienced in 2018/19 were representative of the savings that will be experienced in the coming years. Additionally, this study used recorded rock and brine application rates to estimate the savings that would occur from the expansion of this Pilot project, and from the use of DLA by all Metrolinx Go Stations on the Lakeshore East and West lines within the City of Toronto, all Green P parking lots within 
the City of Toronto, and all King Street streetcar stops. Although the results were accompanied by a degree of uncertainty, this research suggests that DLA was an effective approach for reducing Ryerson $\mathrm{Cl}^{-}$use during the 2018/19 winter season. However, it was also concluded that lowering the application rates and increasing the total pilot area could further increase the $\mathrm{Cl}^{-}$savings experienced at Ryerson and the monetary benefit of adopting DLA. The extrapolation of the results to all areas of Ryerson, to Green P parking lots and to Metrolinx Go Stations also illustrated the environmental and monetary incentives for the use of DLA in those areas. The methodological design used in this study may provide more accurate $\mathrm{Cl}^{-}$savings estimations with increased number of observed salting records. These findings also provide advocacy groups, such as the WWF, with positive case studies which these groups can use to support their efforts to influence organizations to adopt road salt reduction strategies. The results also suggest the utility experienced in 2018/19 were fairly representative of the savings that will be experienced in the coming years. Lastly, the recommendations developed through this analysis may prove useful for improving the methodological design, data recording practices, and ultimately the $\mathrm{Cl}^{-}$ reductions of the Ryerson Road Salt Reduction Project and road salt reduction projects in general. 


\section{References}

Alger, R. G., Adam, E. E., \& Beckwith, E. P. (1994). Controlled Chemical Treatments. National Research Council Strategic Highway Research Program.

Baltrènas, P., \& Kazlauskienè, A. (2009). Sustainable Ecological Development Reducing Negative Effects of Road Maintenance Salts. Technological and Economic Development of Economy, 15(1), 178-188. https://doi.org/10.3846/1392-8619.2009.15.178-188

Beggel, S., \& Geist, J. (2015). Acute effects of salinity exposure on glochidia viability and host infection of the freshwater mussel Anodonta anatina (Linnaeus, 1758). Science of the Total Environment, 502, 659-665. https://doi.org/10.1016/j.scitotenv.2014.09.067

Bonett, D. G., \& Wright, T. A. (2011). Sample size requirements for multiple regression interval estimation. 830(May 2010), 822-830. https://doi.org/10.1002/job

CEQG. (2011). Canadian Water Quality Guidelines for the Protection of Aquatic Life - Uranium. Canadian Environmental Quality Guidelines, 1-9.

City of Toronto. (2016). Salt management guide. (August). Retrieved from https://www.canada.ca/en/environment-climate-change/services/pollutants/road-salts/codepractice-environmental-management.html\#Pre

Corsi, S. R., Graczyk, D. J., Geis, S. W., Booth, N. L., \& Richards, K. D. (2010). A Fresh Look at Road Salt : Aquatic Toxicity and Water-Quality Impacts on Local , Regional , and National. Environmental Science \&Technology, 44(19), 7376-7382.

Crewe, H., \& Gowda, C. (2018). Good Practices for Winter Maintenance in Salt Vulnerable Areas.

Cuelho, E., Harwood, J., Akin, M., \& Adams, E. (2010). Establishing Best Practices of Removing Snow and Ice from California Roadways. (December), 102. Retrieved from

http://trid.trb.org/view.aspx?id=1097964

Cunningham, M. A., Snyder, E., Yonkin, D., Ross, M., \& Elsen, T. (2008). Accumulation of deicing salts in soils in an urban environment. Urban Ecosystems, 11(1), 17-31. https://doi.org/10.1007/s11252007-0031-x

Daley, M. L., Potter, J. D., \& Mcdowell, W. H. (2009). Salinization of urbanizing New Hampshire streams and groundwater: Effects of road salt and hydrologic variability Salinization of urbanizing New Hampshire streams and groundwater : effects of road salt and hydrologic variability. (December). https://doi.org/10.1899/09-052.1

Environment and Climate Change Canada. (2016). Code of Practice: The Environmental Management of Road Salts: Overview of 2013-14 Reported Data in the Context of National Targets. Retrieved from http://www.ec.gc.ca/sels-salts/default.asp?lang=En\&n=F37B47CE-1

Environment Canada. (2001). Priority Substances List Assessment Resport: Road Salts. 181. Retrieved from http://www.statcan.gc.ca/search-recherche/bb/info/3000017-eng.htm

Environment Canada. (2012). Five-year review of progress code of practice for the environmental management of road salts. Retrieved from http://publications.gc.ca/site/eng/9.695258/publication.html

Fay, L., \& Shi, X. (2012). Environmental impacts of chemicals for snow and ice control: State of the 
knowledge. Water, Air, and Soil Pollution, 223(5), 2751-2770. https://doi.org/10.1007/s11270011-1064-6

Fonnesbech, J. K. (2007). Ice Control Technology with 20 Percent Brine on Highways. Transportation Research Record: Journal of the Transportation Research Board, 1741(1), 54-59.

https://doi.org/10.3141/1741-09

Fu, L., Omer, R., \& Jiang, C. (2012). Field Test of Organic Deicers as Prewetting and Anti-Icing Agents for Winter Road Maintenance. Transportation Research Record: Journal of the Transportation Research Board, 2272(1), 130-135. https://doi.org/10.3141/2272-15

Hájková, K., Šmilauer, V., Jendele, L., \& Červenka, J. (2018). Prediction of reinforcement corrosion due to chloride ingress and its effects on serviceability. Engineering Structures, 174(February), 768-777. https://doi.org/10.1016/j.engstruct.2018.08.006

Hintz, W. D., \& Relyea, R. A. (2017). Impacts of road deicing salts on the early-life growth and development of a stream salmonid: Salt type matters. Environmental Pollution, 223, 409-415. https://doi.org/10.1016/j.envpol.2017.01.040

Hossain, K., \& Fu, L. (2016). Optimal Snow and Ice Control for Parking Lots and Sidewalks Optimal Snow and Ice Control of Parking Lots and Sidewalks. (October).

Hossain, S. M. K. (2014). Optimum Deicing and Anti-icing for Snow and Ice Control of Parking Lots and Sidewalks. University of Waterloo.

Hossain, S. M. K., Fu, L., Hosseini, F., Muresan, M., Donnelly, T., \& Kabir, S. (2016). Optimum winter road maintenance: effect of pavement types on snow melting performance of road salts. Canadian Journal of Civil Engineering, 43(9), 802-811. https://doi.org/10.1139/cjce-2016-0010

Howard, K. W. F., \& Maier, H. (2007). Road de-icing salt as a potential constraint on urban growth in the Greater Toronto Area, Canada. Journal of Contaminant Hydrology, 91(1-2), 146-170. https://doi.org/10.1016/j.jconhyd.2006.10.005

Kelly, V. R., Findlay, S. E. G., Schlesinger, W. H., Menking, K., Chatrchyan, A. M., Kelly, V. R., \& Findlay, S. E. G. (2010). Road Salt Moving Towards the Solution Special Report December 2010. The Cary Institute of Ecosystem Studies, (December). Retrieved from http://www.caryinstitute.org/research/reports/road_salt_2010.pdf

Kelsall, D., \& Redelmeier, D. A. (2016). Winter road safety is no accident. Cmaj, 188(4), 241. https://doi.org/10.1503/cmaj.160100

Kilgour, B. W., Gharabaghi, B., \& Perera, N. (2013). Ecological benefit of the road salt code of practice. Water Quality Research Journal of Canada, 49(1), 43-52. https://doi.org/10.2166/wqrjc.2013.129

Kotalik, C. J., Clements, W. H., \& Cadmus, P. (2017). Effects of magnesium chloride road deicer on montane stream benthic communities. Hydrobiologia, 799(1), 193-202. https://doi.org/10.1007/s10750-017-3212-5

Labadia, C. F., \& Buttle, J. . (1996). Road Salt Accumulation in Highway Snow Banks. Hydrological Processes, 10, 1575-1589.

Laffray, X., Alaoui-Sehmer, L., Bourioug, M., Bourgeade, P., Alaoui-Sossé, B., \& Aleya, L. (2018). Effects of sodium chloride salinity on ecophysiological and biochemical parameters of oak seedlings (Quercus 
robur L.) from use of de-icing salts for winter road maintenance. Environmental Monitoring and Assessment, 190(5). https://doi.org/10.1007/s10661-018-6645-z

Li, Y., Fang, Y., Seeley, N., Jungwirth, S., Jackson, E., \& Shi, X. (2013). Corrosion by Chloride Deicers on Highway Maintenance Equipment. Transportation Research Record: Journal of the Transportation Research Board, 2361(1), 106-113. https://doi.org/10.3141/2361-13

Matthews, L., \& Andrey, J. (2017). Operational Winter Severity Indices in Canada - From Concept to Practice Operational Winter Severity Indices in Canada - From Concept to Practice. (January).

Meriano, M., Eyles, N., \& Howard, K. W. F. (2009). Hydrogeological impacts of road salt from Canada's busiest highway on a Lake Ontario watershed (Frenchman's Bay) and lagoon, City of Pickering. Journal of Contaminant Hydrology, 107(1-2), 66-81. https://doi.org/10.1016/j.jconhyd.2009.04.002

Nixon, W., \& DeVries, M. R. (2015). Management Practices for Road Salt in Winter Maintenance.

Ordóñez-Barona, C., Sabetski, V., Millward, A. A., \& Steenberg, J. (2018). De-icing salt contamination reduces urban tree performance in structural soil cells. Environmental Pollution, 234, 562-571. https://doi.org/10.1016/j.envpol.2017.11.101

Oswald, C. J., Giberson, G., Nicholls, E., Wellen, C., \& Oni, S. (2019). Spatial distribution and extent of urban land cover control watershed-scale chloride retention. Science of the Total Environment, 652, 278-288. https://doi.org/10.1016/j.scitotenv.2018.10.242

Perera, N., Gharabaghi, B., \& Noehammer, P. (2009). Stream chloride monitoring program of city of Toronto: Implications of road salt application. Water Quality Research Journal of Canada, 44(2), 132-140.

Pilon, P. ., \& Howard, K. W. F. (1987). Contamination of Subsurface Waters by Road De-Icing Chemicals. Water Quality Research Journal of Canada, 22(1), 157-172.

Ramakrishna, D. M., \& Viraraghavan, T. (2005). Environmental impact of chemical deicers - A review. Water, Air, and Soil Pollution, 166(1-4), 49-63. https://doi.org/10.1007/s11270-005-8265-9

Rasa, K., Peltovuori, T., \& Hartikainen, H. (2006). Effects of de-icing chemicals sodium chloride and potassium formate on cadmium solubility in a coarse mineral soil. Science of the Total Environment, 366(2-3), 819-825. https://doi.org/10.1016/j.scitotenv.2005.08.007

Robinson, H. K., Hasenmueller, E. A., \& Chambers, L. G. (2017). Soil as a reservoir for road salt retention leading to its gradual release to groundwater. Applied Geochemistry, 83, 72-85. https://doi.org/10.1016/j.apgeochem.2017.01.018

Sanzo, D., \& Hecnar, S. J. (2006). Effects of road de-icing salt ( $\mathrm{NaCl}$ ) on larval wood frogs ( Rana sylvatica ). 140. https://doi.org/10.1016/j.envpol.2005.07.013

Schlup, U. (1993). Snow removal and ice control technology. Transportation Research Record, (no 1387), 3-7.

Siegel, L. (2007). Hazard Identification for Human and Ecological Effects of Sodium Chloride Road Salt. In Xxxx.

Stewart, M. G., \& Vu, K. A. T. (2000). Structural reliability of concrete bridge including improved chlorideinclude corrision models. Structural Safety, 22, 313-333. https://doi.org/10.1016/S0167- 


\section{0(00)00018-7}

Transportation Association of Canada. (2013). 11.0 - Successes in Road Salt Management: Case Studies. Syntheses of Best Practices Road Salt Management, (April).

Zhang, X., Hogg, W. D., \& Mekis, E. (2001). Spatial and Temporal Characteristics of Heavy Precipitation Events over Canada. Downsview, Ontario, Canada.

Zhou, S. L., Mcmahon, T. A., Walton, A., \& Lewis, J. (2000). Forecasting daily urban water demand : a case study of Melbourne. 236, 153-164. 